\title{
A Técnica de Geração de Colunas Aplicada a Problemas de Roteamento
}

\author{
Rúbia Mara de Oliveira
}

\author{
Orientador:
}

Prof. Dr. Marcos Nereu Arenales

Dissertação apresentada ao Instituto de Ciências Matemáticas e de Computação ICMC-USP, como parte dos requisitos para obtenção do titulo de Mestre em Ciências de Computação e Matemática Computacional.

\section{USP - São Carlos \\ Julho/2001}

Data da Defesa:

$25 / 04 / 2001$

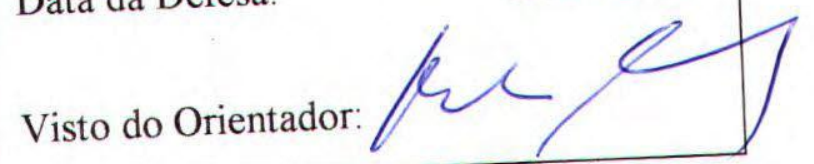


O Senhor é o meu pastor e nada me faltará. Salmos 23:1 
Dedico este trabalho aos meus pais Israel e Iraídes e aos meus irmãos Misael, Érica e Eliseu. 


\section{AGRADECIMENTOS}

Agradecer é uma tarefa difícil...É chegado o momento de lembrar das pessoas que de alguma forma contribuíram para que eu tivesse condições de chegar até aqui. São muitas as pessoas que compartilharam esses momentos, mas agradeço em especial:

Primeiramente a DEUS por estar presente a cada dia e por todas as oportunidades.

Ao Prof. Dr. Marcos Nereu Arenales pela orientação, dedicação, paciência e amizade no decorrer do desenvolvimento deste trabalho.

A Prof ${ }^{a}$ Dr $^{a}$ Vitória M. Pureza e ao Prof. Dr. Edson M. Aguiar pelas valiosas sugestões dadas em meu exame de qualificação, que vieram a contribuir muito com esta dissertação e com meu crescimento.

Ao meu grande amigo Helton pela amizade, carinho, companheirismo e sugestões dadas durante a fase de implementação e muitas outras...enfim por me "socorrer" em momentos difíceis.

Ao meu namorado Sales pelo carinho, amor, amizade, ajuda e momentos felizes juntos.

Aos amigos e professores da UNESP de São José do Rio Preto pelo incentivo e amizade. Em especial à $\operatorname{Prof}^{\mathrm{a}} \mathrm{Dr}^{\mathrm{a}}$ Angela Maria Sita pelo carinho e estímulo desde os tempos de graduação.

Ao meu amigo Ricardo, pela amizade, carinho, sugestões e ajuda durante a fase final deste trabalho.

A todos os amigos aqui conquistados que fizeram e (continuarão fazendo) parte da minha história. São eles: os amigos do laboratório de Otimização, Análise Numérica, Estatística, Computação, Engenharia e Matemática Pura.

Aos professores e funcionários do ICMC-USP pela disponibilidade e atenção com que me trataram.

A toda a minha família pelo incentivo e carinho durante o desenvolvimento desta pesquisa. Em especial aos meus pais Israel e Iraídes e aos meus irmãos Misael, Érica e Eliseu.

Ao CNPq pelo apoio financeiro.

Enfim, às pessoas que direta ou indiretamente colaboraram com este trabalho $\mathrm{e}$ que estiveram presentes quando eu precisava. UM SIMPLES SORRISO FOI MUITO IMPORTANTE. 


\section{RESUMO}

Este trabalho apresenta um estudo teórico da Técnica de Geração de Colunas (GC) aplicada em alguns Problemas de Roteamento de Veículo (PRV). Essa técnica foi inicialmente utilizada para tratar problemas de otimização de grande porte com estruturas especiais[Dantzig \& Wolfe, 1960]. Dentre as diversas classes de problemas de roteamento," revisamos a aplicação dessa técnica a dois casos particulares:

- O problema de roteamento de helicópteros em plataformas marítimas, cujo objetivo minimizar o custo total do transporte;

- O problema de roteamento com janela de tempo, onde a função objetivo é descrita pelo tamanho da frota e o custo do percurso.

Revisamos e implementamos um algoritmo de caminho mínimo com janela de tempo (CMJT). Esse algoritmo surge como um sub-problema do algoritmo Primal Simplex para resolver o problema de partição de conjunto, utilizado para modelar o problema de roteamento com janela de tempo.

Palavras Chaves: Técnica de Geração de Colunas, Problemas de Roteamento de Veículos, Caminho Mínimo com Janela de Tempo. 


\begin{abstract}
This work presents a study about the Column Generation Technique (CG) applied to some Vehicle Routing Problems. The technique was first used to deal with optimization problems having special structures. Among the various classes of routing problems, we review the use of the technique in two specific cases:

- Routing helicopters for crew exchanges on off-shore locations, where the objective is to minimize the total transportation cost;

- Routing with time windows, where the objective function is composed by the size of the fleet and the cost of route.

We review and implement a shortest path algorithm with time windows. This algorithm arises as a sub-problem in the Primal Simplex algorithm to solve the linear relaxation of the set partitioning problem used to model the routing problem with time windows.

Key Words: Column Generation Technique, Vehicle Routing Problems, Shortest Path with Time Windows.
\end{abstract}




\section{Sumário}

1 Introdução 1

1.1 Caracterização dos Problemas de Roteirização de Veículos . . . . . . . . . 3

1.2 Formulação Básica de Um Problema de Roteamento de Veículo . . . . . . . 6

1.3 Objetivos Principais da Pesquisa . . . . . . . . . . . . . 7

1.4 Estrutura da monografia . . . . . . . . . . . . . . 7

2 Otimização Linear e Geração de Colunas $\quad 9$

2.1 Revisão do Método Simplex . . . . . . . . . . . . . . . . . . 9

2.2 O Problema de Corte de Estoque Unidimensional . . . . . . . . . . . . . 12

2.3 O Método Simplex com Geração de Colunas . . . . . . . . . . . . . . . 14

2.4 A Técnica de Geração de Colunas Aplicada ao Problema de Corte de Estoque Unidimensional . . . . . . . . . . . . . . . . . . 15

2.5 Procedimento Heurístico para Resolução do Problema Inteiro . . . . . . . . 16

3 A Técnica de Geração de Colunas Aplicada em um Problema de Roteamento de Helicópteros Para a Troca de Equipes em Plataformas $\begin{array}{ll}\text { Marítimas } & 18\end{array}$

3.1 Considerações Iniciais . . . . . . . . . . . . . . . . . . . . 18

3.2 Descrição do Problema . . . . . . . . . . . . . . . 18

3.3 Modelo de Programação Linear Inteira . . . . . . . . . . . . . . . . . . . 21

3.4 Aplicação da Técnica de Geração de Colunas . . . . . . . . . . . . . . . 22

3.5 Geração de sub-conjuntos de plataformas . . . . . . . . . . . . . . . . . 24

3.6 Algoritmo Simplex com Geração de Colunas . . . . . . . . . . . . . . . 26

3.7 Procedimento de Arredondamento para determinação de solução inteira . . 27

3.8 Considerações Finais . . . . . . . . . . . . . . . . . . . . 28

4 O Uso da Técnica de Geração de Colunas em Problemas de Roteamento com Janela de Tempo 
4.1 Considerações Iniciais . . . . . . . . . . . . . . . . . . . . . . . 29

4.2 Descrição e Formulação do Problema . . . . . . . . . . . . . . . . . . . . . 29

4.3 Formulação por Partição de Conjuntos . . . . . . . . . . . . . . . . . . 31

4.4 Solução do sub-problema . . . . . . . . . . . . . . . . . . . . . 34

4.5 Solução do Problema-Mestre . . . . . . . . . . . . . . . . . . . . 34

4.6 Obtenção de solução inteira . . . . . . . . . . . . . . . . . 35

4.6 .1 O Plano de Corte . . . . . . . . . . . . . . . . 36

4.6 .2 A Ramificação . . . . . . . . . . . . . . . . . . . . . 36

4.7 Considerações Finais . . . . . . . . . . . . . . . . . . . 38

5 O Problema de Caminho Mínimo com Janela de Tempo 45

5.1 Considerações Iniciais . . . . . . . . . . . . . . . . . . . . 45

5.2 Formulação do Problema . . . . . . . . . . . . . . . . . . . 46

5.3 Algoritmo de Ford-Bellman-Moore . . . . . . . . . . . . . . . 46

5.4 Natureza das Etiquetas . . . . . . . . . . . . . . . . . . . . 47

5.5 Relação de Ordem das Etiquetas . . . . . . . . . . . . . . . . . . . . 48

5.6 Algoritmo de Caminho Mínimo com Janela de Tempo . . . . . . . . . . . . 49

5.7 Considerações Finais . . . . . . . . . . . . . . . . . . . . 51

6 Conclusões e Trabalhos Futuros

6.1 Trabalhos Futuros . . . . . . . . . . . . . . . . 55

$\begin{array}{ll}\text { Referências Bibliográficas } & \mathbf{5 6}\end{array}$ 


\section{Lista de Figuras}

3.1 Localização Topográfica das Plataformas onde os Funcionários estão Trabalhando. . . . . . . . . . . . . . . . . . . . 19

3.2 Uma unidade de distância corresponde a $4,5 \mathrm{~km} . \ldots \ldots \ldots$

3.3 Helicóptero Sikorski-61 . . . . . . . . . . . . . . . . . . 20

4.1 Exemplo de uma rede formada por 6 viagens (nós) $\ldots \ldots \ldots \ldots$

4.2 Método Simplex com Geração de coluna . . . . . . . . . . . . . 35

4.3 Representação da $\operatorname{rota} r \ldots \ldots \ldots \ldots \ldots \ldots \ldots$

4.4 Grafo representando o problema em questão . . . . . . . . . . . . 38

4.5 Caminhos ótimos (em tracejado) encontrados após a resolução do problema 44

5.1 Custo $\mathrm{x}$ Tempo de Chegada de etiquetas armazenadas no nó $\mathrm{i} \ldots 49$

5.2 Grafo representando os dados de entrada para o arquivo . . . . . . . . 52

5.3 Grafo representando o caminho mínimo da origem ao destino . . . . . . . 52 


\section{Lista de Tabelas}

1.1 Classificação dos problemas de roteirização pura [Bodin et al., 1983] . . . . 4

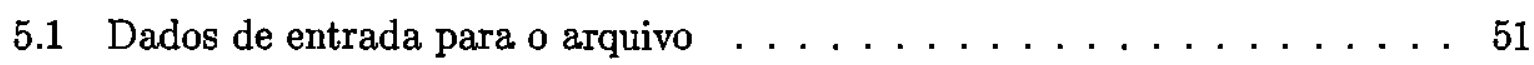

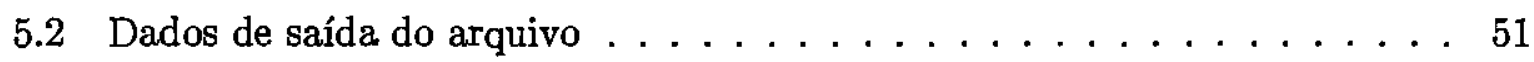




\section{Capítulo 1}

\section{Introdução}

Problemas de Roteamento de Veículos (PRV) têm sido bastante estudados na literatura, com grande impulso na década de 80 após o evento International Workshop on Current and Future Directions in the Scheduling of Vehicles and Crews [Boldin \& Golden, 1981] e a edição especial The state of art in routing and scheduling of vehicles and crews [Bodin et al., 1983].

Os termos roteirização ou roteamento de veículos, embora não encontrados nos dicionários de língua portuguesa, são formas que vêm sendo utilizadas como equivalentes ao inglês "routing" (ou "routeing") para designar o processo de determinação de um ou mais roteiros ou sequiências de paradas a serem cumpridos por veículos de uma frota, objetivando visitar um conjunto de pontos geograficamente dispersos, em locais pré-determinados, que necessitem de atendimento.

Problemas de roteamento de veículos desempenham um papel central no gerenciamento da distribuição de bens ou serviços. Sua importância reflete-se na grande variedade de aplicações, as quais incluem o roteamento de ônibus urbanos, sistemas de coleta de lixo e entrega de periódicos a assinantes, entre ouros. Uma aplicação típica consiste em determinar as rotas a serem operadas por uma frota de veículos que, partindo de uma garagern ou depósito central, deve suprir demandas conhecidas de um conjunto de clientes. Cada cliente é servido por exatamente um veículo e todas as rotas começam e terminam na garagem, tendo como objetivo, minimizar a distância total percorrida.

Quando a definição dos roteiros envolve não só aspectos espaciais ou geográficos, mas também temporais, tais como restrições de horário de atendimento nos pontos a serem visitados, os problemas são então denominados roteirização e programação de veículos [Cunha, 1997]. Complicações adicionais (que resultam na grande variedade de PRVs encontrados na literatura) são obtidas com a inclusão de restrições ou condições de contorno. Dentre as mais comuns incluímos as restrições de: 
(1) capacidade - a cada cliente está associado uma demanda não-negativa e a soma das demandas de qualquer rota não deve exceder a capacidade do veículo;

(2) número de clientes - o número máximo de clientes por rota é limitado por um valor máximo;

(3) tempo total - o comprimento de uma rota é composto pelos tempos de viagens interclientes e tempos dispendidos em cada ponto de demanda, sendo limitado por um valor máximo;

(4) janelas de tempo - cada cliente deve ser visitado dentro de um intervalo de tempo especificado.

A roteirização de veículos é uma das histórias de grande sucesso da Pesquisa Operacional nas últimas décadas. Isto pode ser medido pelo expressivo número de artigos que vem sendo publicados ao longo dos anos na literatura especializada.

O primeiro problema de roteirização a ser estudado foi o do folclórico Caixeiro Viajante (no inglês "traveling salesman problem" ou TSP), que consiste em encontrar o roteiro ou seqüência de cidades a serem visitadas por um caixeiro viajante que minimize a distância total percorrida e assegure que todas as cidades sejam visitadas exatamente uma vez. Desde então, novas restrições vêm sendo incorporadas ao problema do caixeiro viajante, de modo a melhor representar os diferentes tipos de problemas que envolvem roteiros de pessoas e veículos, entre as quais: restrições de horário de atendimento (conhecidas na literatura como janelas de tempo ou janelas horárias); capacidades dos veículos; frota composta de veículos de diferentes tamanhos; duração máxima dos roteiros dos veículos (tempo ou distância); restrições de tipos de veículos que podem atender determinados clientes. Problemas de roteirização de veículos são muitas vezes definidos como problemas de múltiplos caixeiros viajantes com restrições adicionais de capacidade, além de outras que dependem de cada aplicação.

Sob a ótica da otimização, os problemas de roteirização de veículos, incluindo o caso particular do caixeiro viajante, pertencem à categoria conhecida como $N P$-completo (do inglês "NP-hard"), o que significa que os algoritmos conhecidos possuem ordem de complexidade exponencial. Em outras palavras, o esforço computacional para a resolução dos problemas cresce exponencialmente com o tamanho do problema (dado pelo número de pontos a serem atendidos). A título de ilustração, até hoje não são conhecidas as respectivas soluções ótimas para alguns problemas de roteirização com restrição de janelas 
de tempo com apenas 100 nós, propostos por [Solomon, 1986] e que vêm sendo utilizadas para a avaliação comparativa de novos algoritmos propostos na literatura [Cunha, 1997].

Em aplicações práticas, isto significa que não é possível resolver até a otimalidade problemas reais pertencentes à classe $N P$-completo. Consequentemente, os métodos de solução de todos os softwares e aplicativos comerciais encontrados no mercado para roteirização de veículos são heurísticos, isto é, não asseguram a obtenção da solução ótima do ponto de vista matemático.

Essa complexidade matemática dos problemas de roteirização, assim como a sua relevância no contexto logístico atual, explicam o constante interesse em busca de novas estratégias de solução que vem sendo observado desde a década de 60, resultando em um número muito expressivo de artigos publicados na literatura especializada.

Isso decorre do fato que, sendo as estratégias de solução heurísticas, muitas vezes se apoiam em uma abordagem intuitiva na qual a estrutura particular do problema possa ser considerada e explorada de forma inteligente, para a obtenção de uma solução adequada [Cunha, 1997]. Assim, na maioria dos casos, as heurísticas propostas são bastante específicas e particulares, além de não conseguirem obter boas soluções para problemas com características ou restrições, às vezes, pouco diferentes daquelas para as quais foram desenvolvidas. Em outras palavras, roteirização de veículos é uma área onde uma solução para um determinado tipo de problema e dados pode não ser adequada para outro problema similar.

\subsection{Caracterização dos Problemas de Roteirização de Veículos}

A roteirização de veículos envolve um conjunto muito grande de diferentes tipos de problemas. Nesta seção serão apresentadas algumas propostas encontradas na literatura que tentam caracterizar o universo de problemas de roteirização.

[Bodin et al., 1983] apresentaram o primeiro trabalho abrangente que retratava o "estado-da-arte" da modelagem de problemas de roteirização e programação de veículos e tripulações. Ainda hoje é considerada uma das importantes referências sobre o assunto, pois são considerados vários tipos de problemas. Para os autores, os problemas de roteirização podem ser do tipo roteirização pura ou combinados de roteirização e programação. Nos problemas de roteirização pura, restrições temporais não são consideradas para a definição dos roteiros e das sequiênecias de atendimentos (coletas ou entregas). As 
estratégias de solução são direcionadas aos aspectos espaciais da localização dos pontos a serem atendidos. Os principais tipos de problemas de roteirização pura são relacionados na tabela 1.1.

\begin{tabular}{|c|c|c|c|c|c|}
\hline Denominação & $\begin{array}{l}\text { Numero } \\
\text { de } \\
\text { reteiras }\end{array}$ & $\begin{array}{l}\text { Tomalinasão } \\
\text { dos } \\
\text { vientes }\end{array}$ & $\begin{array}{l}\text { Limite de } \\
\text { eapacidade } \\
\text { iros Viculos }\end{array}$ & $\begin{array}{l}\text { Número } \\
\text { de bases }\end{array}$ & Demandas \\
\hline $\begin{array}{l}\text { Problema do } \\
\text { caixeiro viajante }\end{array}$ & um & nós & não & uma & determinísticas \\
\hline $\begin{array}{l}\text { Problema do } \\
\text { carteiro chinês }\end{array}$ & um & $\operatorname{arcos}$ & não & uma & deterministicas \\
\hline $\begin{array}{l}\text { Problema de } \\
\text { múltiplos } \\
\text { caixeiros viajantes }\end{array}$ & múltiplos & nós & não & uma & determinísticas \\
\hline $\begin{array}{l}\text { Problema de } \\
\text { roteirização em } \\
\text { nós com uma } \\
\text { única base }\end{array}$ & múltiplos & nós & $\operatorname{sim}$ & uma & determinísticas \\
\hline $\begin{array}{l}\text { Problema de } \\
\text { roteirização em } \\
\text { nós com múltiplas } \\
\text { bases }\end{array}$ & múltiplos & nós & $\operatorname{sim}$ & múltiplas & determinísticas \\
\hline $\begin{array}{l}\text { Problema de } \\
\text { roteirização em } \\
\text { nós com demandas } \\
\text { incertas }\end{array}$ & múltiplos & nós & $\operatorname{sim}$ & uma & estocásticas \\
\hline $\begin{array}{l}\text { Problema de } \\
\text { roteirização em } \\
\text { arcos com limite } \\
\text { de capacidade }\end{array}$ & múltiplos & $\operatorname{arcos}$ & $\operatorname{sim}$ & uma & deterministicas \\
\hline
\end{tabular}

Tabela 1.1: Classificação dos problemas de roteirização pura [Bodin et al., 1983].

Deve-se observar que os problemas listados na tabela 1.1, derivam do problema clássico do caixeiro viajante, com exceção do problema do carteiro chinês, em que a demanda se localiza nos arcos ao invés de nós e a otimização envolve os percursos ociosos, já que o veículo precisa passar em todos os arcos uma vez para atendimento.

Segundo [Bodin et al., 1983], a maioria dos problemas combinados de roteirização e programação, ou simplesmente problemas de roteirização e programação ocorrem em situações em que estão presentes restrições de janelas de tempo (horário de atendimento) e/ou precedência entre tarefas (coleta deve preceder a entrega e ambas devem estar alocadas ao mesmo veículo). Os principais problemas típicos de roteirização e programação apontados pelos autores são os seguintes: 
- o problema de roteirização e programação de ônibus escolares para atendimento de um conjunto de escolas;

- o problema de definição de roteiros e programação de serviços de coleta de resíduos domiciliares e de varreção de ruas semelhante ao problema do caixeiro chinês, porém com restrições de capacidade dos veículos, de duração máxima da jornada e de janelas de tempo associadas aos horários de proibição de estacionamento, de forma a possibilitar a execução do serviço de varreção;

- o problema de roteirização e programação de serviços de transporte de pessoas, conhecidos como "dial-a-ride", em geral para o transporte porta-a-porta de idosos e deficientes; cada usuário possui locais de origem e de destino distintos e eventualmente janelas de tempo. Com isso, a precedência entre tarefas é uma restrição fundamental a ser considerada.

Os autores consideraram ainda uma terceira categoria que abrange problemas de programação de veículos e tripulações, nos quais os aspectos espaciais já estão definidos (roteiros ou seqüências de viagens a serem realizadas), restando definir a alocação de veículos e tripulações ao conjunto de viagens programadas. Problemas de programação de veículos e tripulações são encontrados no transporte aéreo, ferroviário, por ônibus, etc.

Uma outra classificação dos diversos problemas de roteamento e programação de veículos baseada nos ambientes operacionais e objetivos a serem alcançados é apresentada por [Cunha, 2000]:

- problemas relativos ao transporte de passageiros: programação de linhas de ônibus; de sistemas de táxi; de sistemas de transporte de pessoas, em geral idosos e deficientes, conhecidos como "dial-a-ride"; de transporte de escolares por ônibus, entre outros;

- problemas de prestação de serviços: roteirização e programação de equipes de reparos ou de serviços públicos, tais como coleta de lixo, entrega postal, varreção de ruas e leitura de parquímetros, equipes em plataformas marítimas, entre outros;

- problemas relativos ao transporte de carga (coleta e distribuição).

Todos os tipos de problemas citados acima são de natureza essencialmente operacional, ou seja, fazem parte das tarefas rotineiras de programação da frota, realizadas regularmente com periodicidade de curto prazo, em geral diária ou semanal. 
Além desses, são encontrados na literatura problemas de roteirização de natureza mais tática (ou estratégica) do que operacional, tais como problemas de estoque e roteirização, nos quais a programação dos atendimentos deve levar em consideração não só aspectos espaciais e os custos dos roteiros, como também questões como o nível de estoque; problemas de faturamento e roteirização, nos quais é preciso definir simultaneamente quem vai ser atendido a cada dia de um período pré-determinado entre outros.

\subsection{Formulação Básica de Um Problema de Rotea- mento de Veículo}

Formular o problema de roteamento de veículos não é uma tarefa trivial. Uma das formulações mais utilizadas, na qual baseiam-se diversos métodos de solução é a de [Fisher \& Jaikumar, 1981] descrita a seguir.

Minimizar $z=\sum_{i, j, k} c_{i j} x_{i j k}$

sujeito a:

$$
\begin{array}{lr}
\sum_{k} y_{i k}=1 & i=2, \ldots, n \\
\sum_{k}^{k} y_{i k}=m & i=1 \\
\sum_{i} q_{i} y_{i k} \leq Q_{k} & k=1, \ldots, m \\
\sum_{j} x_{i j k}=\sum_{j} x_{j i k}=y_{i k} & i=1, \ldots, n, k=1, \ldots, m \\
\sum_{i, j \in S} x_{i j k} \leq|S|-1 & \forall S \subseteq\{2, \ldots, n\}, k=1, \ldots, m \\
y_{i k} \in\{0,1\} & i=1, \ldots, n k=1, \ldots, m \\
x_{i j k} \in\{0,1\} & k=1, \ldots, n k=1, \ldots, m
\end{array}
$$

onde:

$$
\begin{aligned}
& x_{i j k}=\left\{\begin{array}{ll}
1 & \text { quando o veículo } k \text { visita o cliente } j \text { imediatamente após o cliente } i \\
0 & \text { caso contrário. }
\end{array} .\right. \\
& y_{i k}= \begin{cases}1 & \text { se o cliente } i \text { é visitado pelo veículo } k \\
0 & \text { caso contrário. }\end{cases} \\
& q_{i}: \text { a demanda do cliente } i . \\
& Q_{k}: \text { a capacidade do veículo } k .
\end{aligned}
$$


$c_{i j}:$ o custo de percorrer o trecho de $i$ a $j$.

As restrições (1.1) garantem que cada cliente seja visitado por exatamente um veículo, as restrições (1.2) garantem que os $m$ veículos partem do depósito, as restrições (1.3) obrigam que as capacidades dos veículos não sejam ultrapassadas, as restrições (1.4) garantem que os veículos não parem suas rotas em um cliente e as restrições (1.5) constituem as tradicionais restrições de eliminação de sub-rotas.

\subsection{Objetivos Principais da Pesquisa}

Problemas de Roteamento de Veículos são, em geral, da classe NP-Difícil. Em virtude desta característica não se aplica, na prática, métođos exates para resolução do problema de roteamento. É comum o emprego de métodos heurísticos, por exemplo, a Técnica de Geração de Colunas com heurísticas de arredondamento. Essa técnica foi inicialmente utilizada para tratar problemas de otimização de grande porte com estruturas especiais, por exemplo, a estrutura bloco-angular [Dantzig \& Wolfe, 1960] na qual os problemas com grande número de restrições são transformados em outros problemas com grande números de variáveis (colunas). Em 1961, essa técnica foi usada por [Gilmore \& Gomory, 1961] para resolver problema de corte e empacotamento. Desde então, tem sido utilizada em muitos outros problemas de otimização combinatória. O principal objetivo deste trabalho consistiu em revisar a aplicação da Técnica de Geração de Colunas em problemas de roteamento de veículos. Nessa técnica, parte da natureza combinatória do problema é transferida para um sub-problema (resolvido a cada iteração) que consiste de problemas bem estudados, tais como, problema da mochila, caminho mínimo, entre outros.

\subsection{Estrutura da monografia}

No capítulo 2, apresentamos o Método Simplex e o Problema de Corte de Estoque objetivando uma melhor compreensão da técnica de geração de colunas. Um procedimento heurístico para obter soluções inteiras é também apresentado neste capítulo.

No capítulo 3, é apresentada a técnica de geração de colunas aplicada a um problema de roteamento de helicópteros em plataformas marítimas, cujo objetivo é minimizar 
o custo total deste transporte.

No capítulo 4, é abordado um pouco mais da teoria relacionada com geração de colunas, onde também apresenta-se um método que resolve otimamente o problema de rotas com janela de tempo.

No capítulo 5, descreveremos com detalhes o algoritmo de Caminho Mínino com Janela de Tempo.

Por fim, as conclusões e perspectivas deste trabalho são apresentadas no capítulo 6 . 


\section{Capítulo 2}

\section{Otimização Linear e Geração de Colunas}

Neste capítulo apresentamos uma breve revisão do método simplex e da técnica de geração de colunas que serão utilizadas nos capítulos subsequentes, aplicadas a problemas de roteamento. Para ilustrar, introduzimos o problema de corte de estoque e descrevemos um procedimento heurístico para resolução do problema inteiro.

\subsection{Revisão do Método Simplex}

Considere o problema apresentado em sua forma matricial:

$$
\begin{array}{cl}
\text { Minimizar } & f(x)=c^{T} x \\
\text { Sujeito } a: & A x=b, \\
& x \geq 0 .
\end{array}
$$

onde $A \in \mathbb{R}^{m \times n}$ e posto $(A)=m$. Observe que as restrições de demanda estão sendo consideradas em forma de igualdade, mas, poderiam ter sido formuladas com desigualdades. Isto não apresenta dificuldade, pois podemos considerar variáveis de folgas e transformar as restrições com desigualdades em restrições de igualdade. Teremos tantas variáveis de folga quanto forem as restrições de desigualdade.

Consideremos agora uma partição nas colunas da matriz $A$ da seguinte forma: $(A)=(B, N)$, tal que $I B$ é o conjunto de índices das variáveis básicas e $I N$ o conjunto de índices das variáveis não-básicas. Assim a matriz $B \in \mathbb{R}^{m \times n}$ é formada de $m$ colunas da matriz $A$ e é inversivel. A mesma partição será feita no vetor das variáveis: $x=\left(x_{B}, x_{N}\right)$, onde $x_{B}$ é chamado vetor de variáveis básicas e $x_{N}$ vetor de variáveis não-básicas.

Desta forma:

$$
\begin{array}{ll}
A x=b & \Leftrightarrow \\
B x_{B}+N x_{N}=b & \Leftrightarrow \\
x_{B}=B^{-1} b-B^{-1} N x_{N} . &
\end{array}
$$


A solução particular $\widehat{x}$ obtida por $\widehat{x}_{B}=B^{-1} b, \widehat{x}_{N}=0$, é chamada solução básica. Se $\widehat{x}_{B}=B^{-1} b \geq 0$, então a solução básica é primal-factível e dizemos que a partição básica também é primal-factível. Os coeficientes da função objetivo, com a partição dada acima, também são particionados da seguinte forma:

$$
c^{T}=\left(c_{B}, c_{N}\right)^{T}
$$

O vetor $\pi^{T}=c_{B}^{T} B^{-1}$ é o que chamamos de vetor multiplicador simplex. Se

$$
c_{j}-\pi^{T} a_{j} \geq 0, j=1, \ldots, n
$$

solução básica é ótima.

A estratégia simplex, que consiste na perturbação da solução básica, será agora apresentada. Esta perturbação será feita da seguinte maneira:

- escolha $k \in I N$, tal que: $c_{k}-\pi^{T} a_{k}<0$;

- faça:

$$
\begin{aligned}
& x_{k}=\varepsilon \geq 0, \\
& x_{j}=0 \quad \forall j \in I N-\{k\} .
\end{aligned}
$$

A estratégia simplex produz uma nova solução dada por:

$$
\left\{\begin{array}{l}
x_{B}=\widehat{x}_{B}+\varepsilon y \\
x_{N}=\varepsilon e_{k}
\end{array}\right.
$$

onde $y=-B^{-1} a_{k}$ e $e_{k}=(0, \ldots, 1,0, \ldots, 0)^{T} \in \mathbb{R}^{n-m}$, com 1 na k-ésima componente.

O valor da função objetivo será dada por:

$$
f(x)=f(\widehat{x})+\left(c_{k}-\pi^{T} a_{k}\right) \varepsilon
$$

onde a expressão $\left(c_{k}-\pi^{T} a_{k}\right)$ é chamada de custo relativo.

A direção $d \in \mathbb{R}^{n}$, dada por $d=\left(d_{B}, d_{N}\right)^{T}=\left(y, e_{k}\right)^{T}$, define uma perturbação da solução básica e será chamada direção simplex. De (2.6), podemos determinar o maior valor do passo $\varepsilon$, impondo $x_{B} \geq 0$ :

$$
\widehat{\varepsilon}=-\frac{\widehat{x}_{B_{l}}}{y_{l}}=\min \left\{-\frac{\widehat{x}_{B_{i}}}{y_{l}} \text { tal que } y_{i}<0, i=1, \ldots, m\right\}
$$

Naturalmente, se $y_{i} \geq 0, i=1, \ldots, m$, não haverá limitante para o passo, então $f(x) \rightarrow-\infty$, ou seja, a direção encontrada é um raio de descida e o problema não tem solução ótima. 
Para esta escolha de $\varepsilon$ a $l$-ésima componente de $x_{B}$ se anula enquanto que apenas uma variável de $x_{N}$, que corresponde à $k$-ésima componente, torna-se positiva. Isto sugere uma troca de componentes resultando numa nova partição que será básica primalfactivel. Desta forma, enquanto a solução básica dual for infactível, podemos repetir o procedimento acima, descrevendo o Método Primal-Simplex.

\section{Algoritmo Primal Simplex}

Fase I: Encontre uma partição básica primal-factível: $A=(B, N)$

(Se necessário, utilizar o método das variáveis artificiais)

Faça PARE=FALSO, $I T=0$

Fase II: Enquanto NÃO PARE, faça:

Passo 1: Determine a solução básica primal factível: $x_{B}=B^{-1} b$

Passo 2: Teste de Otimalidade

- Determine a solução básica dual: $\pi^{T}=c_{B}^{T} B^{-1}$

- Determine o menor custo relativo

$$
c_{k}-\pi^{T} a_{k}=\text { mínimo }\left\{c_{j}-\pi^{T} a_{j}: j \in I N\right\}
$$

- Se $c_{k}-\pi^{T} a_{k} \geq 0$, então a solução na iteração $I T$ é ótima

PARE $=$ VERDADE

Passo 3: Determine a direção Simplex: $y=-B^{-1} a_{k}$

Passo 4: Determine o valor

$$
\varepsilon^{0}=-\frac{x_{B l}^{0}}{y_{l}}=\text { mínimo }\left\{-\frac{x_{B_{i}}^{0}}{y_{i}}: y_{i}<0 \text { e } i=1,2, \ldots, m\right\}
$$

Se y $\geq 0$, então o problema não tem solução ótima finita.

PARE $=$ VERDADE

Passo 5: Atualize a partição básica:

$$
\begin{aligned}
& a_{B_{l}} \leftrightarrow a_{k} \\
& I T=I T+1
\end{aligned}
$$




\subsection{O Problema de Corte de Estoque Unidimensional}

A fim de apresentar a metodologia de Geração de Colunas, ilustraremos rapidamente sua utilização no problema de corte de estoque unidemensional. Este problema foi selecionado por ser um didático e de fácil compreensão. Onde cada coluna gerada corresponderá a um padrão de corte. Assim, em seguida será apresentado alguns conceitos referentes ao problema de corte e a aplicação da técnica de geração de colunas.

Problemas de corte de estoque são essenciais no planejamento da produção em várias indústrias, como na indústria de papel, aço, textil, entre outras. Descreveremos o problema de corte de estoque, cujo o objetivo é atender a uma demanda de itens, os quais são obtidos cortando-se os objetos em estoque com menor custo possível. Por simplicidade, supomos que os objetos em estoque possuam os mesmos comprimentos L e estão disponíveis num número ilimitado.

Definição 1: Chamamos de padrão de corte a maneira como um objeto em estoque é cortado para a produção de itens demandados. A um padrão de corte associamos um vetor $m$-dimensional que contabiliza os itens produzidos

$$
a=\left(\alpha_{1}, \alpha_{2}, \ldots, \alpha_{m}\right)
$$

onde $\alpha_{i}$ indica a quantidade de itens do tipo $i$ no padrão de corte. Além disso, dois padrões de corte que tenham o mesmo vetor associado são chamados equivalentes.

Definição 2: Um padrão de corte que produza apenas um tipo de item é chamado padrão de corte homogêneo. Em outras palavras, um padrão de corte é homogêneo se o vetor associado tem apenas uma coordenada não-nula: $a=\left(0, \ldots, \alpha_{i}, \ldots, 0\right), \alpha_{i} \neq 0$.

Note que sempre teremos $m$ padrões homogêneos cujos vetores associados definem uma matriz diagonal. Tais padrões permitem encontrar uma solução primal inicial (FASE I).

Um vetor $a=\left(\alpha_{1}, \alpha_{2}, \ldots, \alpha_{m}\right)$, corresponde a um padrão de corte se, e somente se, satisfizer as restrições do problema abaixo:

$$
\begin{aligned}
& l_{1} \alpha_{1}+l_{2} \alpha_{2}+\cdots+l_{m} \alpha_{m} \leq L \\
& \alpha_{1} \geq 0, \ldots, \alpha_{m} \geq 0 \text { e inteiros }
\end{aligned}
$$

onde $L$ é o comprimento do objeto. 
A modelagem matemática do problema de corte de estoque pode ser feita em duas etapas:

$1^{\circ}$ etapa: Defina todas as possíveis maneiras de cortar os objetos em estoque, isto é; defina todos os possíveis padrões de corte.

$2^{\circ}$ etapa: Decida quantas vezes cada padrão de corte será utilizado para atender a demanda.

Note que na primeira etapa temos um problema essencialmente combinatório, enquanto que na etapa seguinte, um problema contábil.

Apresentaremos a formulação de um modelo básico utilizando apenas um tipo de barra em estoque em quantidade ilimitada. Neste caso, o estoque é composto de barras de comprimento $L$, em quantidade suficiente para atender a demanda $d_{1}, d_{2}, \ldots, d_{m}$ dos ítens de comprimento $l_{1}, l_{2}, \ldots, l_{m}$, respectivamente, e o custo de cada barra é $\$ C$. Objetiva-se atender a demanda ao custo mínimo.

Conforme já mencionamos anteriormente, procedemos à modelagem matemática em duas etapas:

- Defina todos os possíveis padrões de corte, isto é, determine todas as possíveis soluções do problema abaixo:

$$
\begin{aligned}
& l_{1} \alpha_{1}+l_{2} \alpha_{2}+\cdots+l_{m} \alpha_{m} \leq L \\
& \alpha_{1} \geq 0, \ldots, \alpha_{m} \geq 0 \text { e inteiros }
\end{aligned}
$$

Suponha as $n$ possíveis soluções:

$$
a_{1}=\left(\begin{array}{c}
\alpha_{11} \\
\alpha_{21} \\
\vdots \\
\alpha_{m 1}
\end{array}\right), \quad a_{2}=\left(\begin{array}{c}
\alpha_{12} \\
\alpha_{22} \\
\vdots \\
\alpha_{m 2}
\end{array}\right), \ldots, a_{n}=\left(\begin{array}{c}
\alpha_{1 n} \\
\alpha_{2 n} \\
\vdots \\
\alpha_{m n}
\end{array}\right)
$$

- Seja $x_{j}=$ número de vezes que o objeto é cortado usando o padrão $j$.

Resolva o seguinte problema de otimização linear:

$$
\begin{array}{ll}
\text { Minimizar } & f(x)=C\left(x_{1}+x_{2}+\cdots+x_{n}\right) \\
\text { Sujeito } a: & a_{1} x_{1}+a_{2} x_{2}+\cdots+a_{n} x_{n}=d \\
& x_{1} \geq 0, x_{2} \geq 0, \ldots, x_{n} \geq 0, x_{j} \text { e inteiro }
\end{array}
$$

A condição de integralidade sobre as variáveis $x_{j}$ será abandonada e uma heurística para a obtenção da solução inteira será discutida na seção 2.5. Em notação matricial, o problema (2.12) é escrito por: 


$$
\begin{array}{ll}
\text { Minimizar } & f(x)=c^{T} x \\
\text { Sujeito a }: & A x=d \\
& x \geq 0,
\end{array}
$$

onde cada coluna da matriz $A \in \mathbb{R}^{m \times n}$ é um vetor associado a um padrão de corte $\mathrm{e}$ $c^{T}=(c, c, \ldots, c) \in \mathbb{R}^{N}$.

Observe que minimizar a função objetivo custo, neste caso, corresponde a minimizar o número de objetos (barras) cortados:

$$
\text { Minimizar } f(x)=x_{1}+x_{2}+\cdots+x_{n}
$$

isto é, sem perda de generalidade, podemos adotar $c_{j}=1, j=1,2, \ldots, n$.

\subsection{O Método Simplex com Geração de Colunas}

O processo de geração de colunas é adequado ao Método Simplex para determinar a nova coluna que deverá entrar na base melhorando a solução. A escolha da coluna a entrar na base pode ser bastante complexa devido ao grande número de colunas a serem investigadas. Este processo foi proposto por [Gilmore \& Gomory, 1961], e consiste em encontrar a coluna $j$, com o menor custo relativo, resolvendo-se um sub-problema.

Considere o problema de otimização linear e suponha que o número de variáveis $n$ seja muito grande. Ao aplicarmos o Método Primal-Simplex, necessitamos de uma base primal factível $B$ que produz a solução básica primal factível:

$$
x=\left(x_{B}, x_{N}\right) \quad \text { onde } \quad x_{B}=B^{-1} b \text { e } x_{N}=0,
$$

e o vetor multiplicador simplex:

$$
\pi^{T}=c_{B}^{T} B^{-1}
$$

Para verificar a otimalidade da solução básica $x$, determinamos a variável $x_{k}$ com o menor custo relativo, o que sugere o seguinte sub-problema:

$$
c_{k}-\pi^{T} a_{k}=\operatorname{minimo}\left\{c_{j}-\pi^{T} a_{j}, j=1,2, \ldots, n\right\} .
$$

Em alguns problemas, as colunas da matriz $A$ são calculadas de modo a satisfazer algumas propriedades. 
A enumeração completa de todas as colunas da matriz $A$ é para muitos problemas, um trabalho computacionalmente impossivel, pois pode atingir vários milhões de colunas. Entretanto, sabemos da teoria da otimização linear que apenas $m$ colunas na matriz $A$ serão necessárias para descrever uma solução ótima, isto é, uma solução básica de modo que não precisemos armazenar a matriz $A$ completa.

Considere $a=\left(\alpha_{1}, \alpha_{2}, \ldots, \alpha_{m}\right)$, uma coluna de $A$ e suponha que o coeficiente na função objetivo seja dado por:

$$
c(a)=\gamma_{0}+\sum_{i=1}^{m} \gamma_{i} \alpha_{i}
$$

onde $\gamma_{i}$ são conhecidos. Assim, o custo relativo da variável, cuja coluna é dada por $a$, pode ser determinado por:

$$
c(a)-\pi^{r} a_{k}=\gamma_{0}+\sum_{i=1}^{m} \gamma_{i} \alpha_{i}-\sum_{i=1}^{m} \pi_{i} \alpha_{i}=\gamma_{0}+\sum_{i=1}^{m}\left(\gamma_{i}-\pi_{i}\right) \alpha_{i},
$$

e o sub-problema, para determinar a coluna de $A$ a entrar na base, pode se escrito por:

$$
\begin{array}{ll}
\text { Minimizar } & \gamma_{0}+\sum_{i=1}^{m}\left(\gamma_{i}-\pi_{i}\right) \alpha_{i} \\
\text { Sujeito a }: & \left(\alpha_{1}, \alpha_{2}, \ldots, \alpha_{m}\right) \in X
\end{array}
$$

onde $X$ descreve o subconjunto de $R^{m}$.

As colunas da matriz $A$ não estão disponíveis, e serão geradas pela solução do sub-problema (2.20), devendo ser alterado apenas o passo 2. A seguir, mostramos como esta técnica pode ser utilizada na resolução do problema de corte de estoque.

\subsection{A Técnica de Geração de Colunas Aplicada ao Problema de Corte de Estoque Unidimensional}

Consideremos inicialmente o problema (2.10), onde as barras de comprimento $L$ devem ser cortadas em pedaços $l_{i}$ em quantidades $\left(d_{i}, i=1, \ldots, \mathrm{m}\right)$. As colunas da matriz $A$ são bem determinadas por:

$$
X=\left\{a=\left(\alpha_{1}, \alpha_{2}, \ldots, \alpha_{m}\right): l_{1} \alpha_{1}+l_{2} \alpha_{2}+\cdots+l_{m} \alpha_{m} \leq L, \alpha_{i} \geq 0 \text { e inteiro, } i=1, \ldots, m\right\} .
$$

Primeiramente precisaremos determinar uma base inicial. As colunas da matriz $A$ são facilmente construídas, considerando-se padrões de corte homogêneos, cujos vetores 
associados constituem $m$ vetores linearmente independentes de $X$ :

$$
a=\left(0, \ldots, \alpha_{i j}, \ldots, 0\right), \quad i=1, \ldots, m,
$$

onde $\alpha_{i j}=\left\lfloor L / l_{i}\right\rfloor$ e $\lfloor x\rfloor$ é o menor inteiro $\leq x$. Assim podemos construir uma base inicial:

$$
B=\left[\begin{array}{cccc}
\alpha_{11} & 0 & \cdots & 0 \\
0 & \alpha_{22} & \cdots & 0 \\
\vdots & \vdots & \ddots & \vdots \\
0 & 0 & \cdots & \alpha_{m m}
\end{array}\right]
$$

Como os coeficientes da função objetivos são iguais a um, ou seja, $c(a)=\gamma_{0}=$ $1\left(\gamma_{i}=0, i=1, \ldots, m\right)$, segue que $o$ sub-problema $(2.20)$ é escrito por:

$$
\begin{array}{ll}
\text { Minimizar } & 1-\sum_{i=1}^{m} \pi_{i} \alpha_{i} \\
\text { Sujeito } a: & \sum_{\substack{i=1 \\
m}} l_{i} \alpha_{i} \leq L \\
& \alpha \geq 0 \text { e inteiro, } i=1, \ldots, m .
\end{array}
$$

Equivalenternente, temos o problema da mochila:

$$
\begin{array}{ll}
\text { Maximizar } & \sum_{i=1}^{m} \pi_{i} \alpha_{i} \\
\text { Sujeito } a: & \sum_{\substack{i=1 \\
m}}^{m} l_{i} \alpha_{i} \leq L \\
& \alpha_{i} \geq 0 \text { e inteiro, } i=1, \ldots, m .
\end{array}
$$

\subsection{Procedimento Heurístico para Resolução do Pro- blema Inteiro}

A utilização de heurísticas para se obter uma solução inteira a partir da solução relaxada do problema de corte de estoque unidimensional ocorre com freqüência na literatura. [Wäscher \& Gau, 1996] reúnem essas heurísticas e as dividem em Métodos de Padrões Básicos, Métodos do Problema Residual e Métodos Compostos. Uma extensão deste trabalho para o problema de corte bidimensional pode ser visto em [Pinto, 1999].

Nesta seção, mostramos um problema de programação linear inteira, que será relaxado com respeito à integralidade, sendo resolvido utilizando a técnica de geração de colunas (apresentada na seção anterior deste capítulo). Ao obter uma solução com variáveis não inteiras, fazemos um arredondamento para o inteiro inferior, resultando em outro problema residual que será tratado da mesma forma, e assim por diante. Este 
procedimento termina quando o arredondamento para o inteiro inferior resulta somente em freqüências nulas. Mas, com este procedimento algumas demandas, para somente alguns itens, ainda terão que ser satisfeitas, resultando assim num problema residual pequeno e que poderá ser resolvido como um problema bin-packing ou heurísticas simples. Veja [Pinto, 1999].

Para ficar mais claro descrevemos o algoritmo deste procedimento da seguinte forma:

Primeiramente, consideremos o problema na seguinte forma matricial.

$$
\begin{array}{ll}
\text { Minimizar } & f(x)=c^{T} x \\
\text { sujeito } a: & A x \geq d \\
& x \geq 0 \text { e inteiro }
\end{array}
$$

Para resolver o problema (2.26) utilizamos o seguinte método heurístico:

1. Encontrar inicialmente uma solução ótima para o problema relaxado contínuo, utilizando a técnica de geração de colunas [Gilmore \& Gomory, 1965], onde uma solução geralmente não-inteira $\tilde{x}$ é obtida.

2. Fazer o truncamento: $\lfloor\tilde{x}\rfloor$ (maior inteiro $\leq \tilde{x}$ ). Isto resulta numa falta, ou seja, nem toda a demanda será atendida, restando ainda $r=d-A[\tilde{x}\rfloor$ unidades a serem produzidas. Este procedimento produz um novo problema inteiro, denominado problema residual:

$$
\begin{aligned}
\text { Minimizar } & f(y)=c^{T} y \\
\text { sujeito } a: & A y \geq r \\
& y \geq 0 \text { e inteiro }
\end{aligned}
$$

3. Resolver o problema residual (2.27) utilizando também a técnica de geração de colunas (integralidade relaxada). Com isso, $\tilde{y}$ é obtido.

4. Se $\lfloor\tilde{y}\rfloor=0$, então: utilizar uma heurística simples até atender toda a demanda restante.

$$
\text { Senão, fazer : } \begin{aligned}
& x \leftarrow\lfloor\tilde{x}\rfloor+\lfloor\tilde{y}\rfloor \\
& r \leftarrow r-A\lfloor\tilde{y}\rfloor
\end{aligned}
$$

e repetir o passo 3 . 


\section{Capítulo 3}

\section{A Técnica de Geração de Colunas Aplicada em um Problema de Roteamento de Helicópteros Para a Troca de Equipes em Plataformas Marítimas}

\subsection{Considerações Iniciais}

Neste capítulo abordamos o problema estudado por [Sierksma \& Tijssen, 1998] cujo propósito é desenvolver um programa para atender a demanda de trocas de equipes de funcionários em várias plataformas marítimas, de tal modo que o custo total deste transporte seja tão baixo quanto possível. O problema é formulado como um modelo de Programação Linear Inteiro e resolvido por meio de Técnica de Geração de Colunas, incluindo resoluções de Problemas do tipo Caixeiro Viajante (PCV). Como a solução final precisa ser inteira, um procedimento de arredondamento para obter tal solução será desenvolvido.

\subsection{Descrição do Problema}

Em 1962, os países ao redor do Mar do Norte começaram a fazer perfurações submarítimas, motivados pelo descobrimento de um grande campo de gás. Desde então, muitas plataformas de produção foram construídas. O transporte dos funcionários para as plataformas era feito por helicópteros com base na Holanda. O objetivo deste estudo resulta em um programa que atenda à demanda de trocas de funcionários de várias plataformas, de modo que o custo total do transporte seja tão baixo quanto possível. 
A localização das plataformas onde os funcionários estão trabalhando pode ser visualizada na Figura 3.1 , onde serão consideradas somente 51 plataformas.

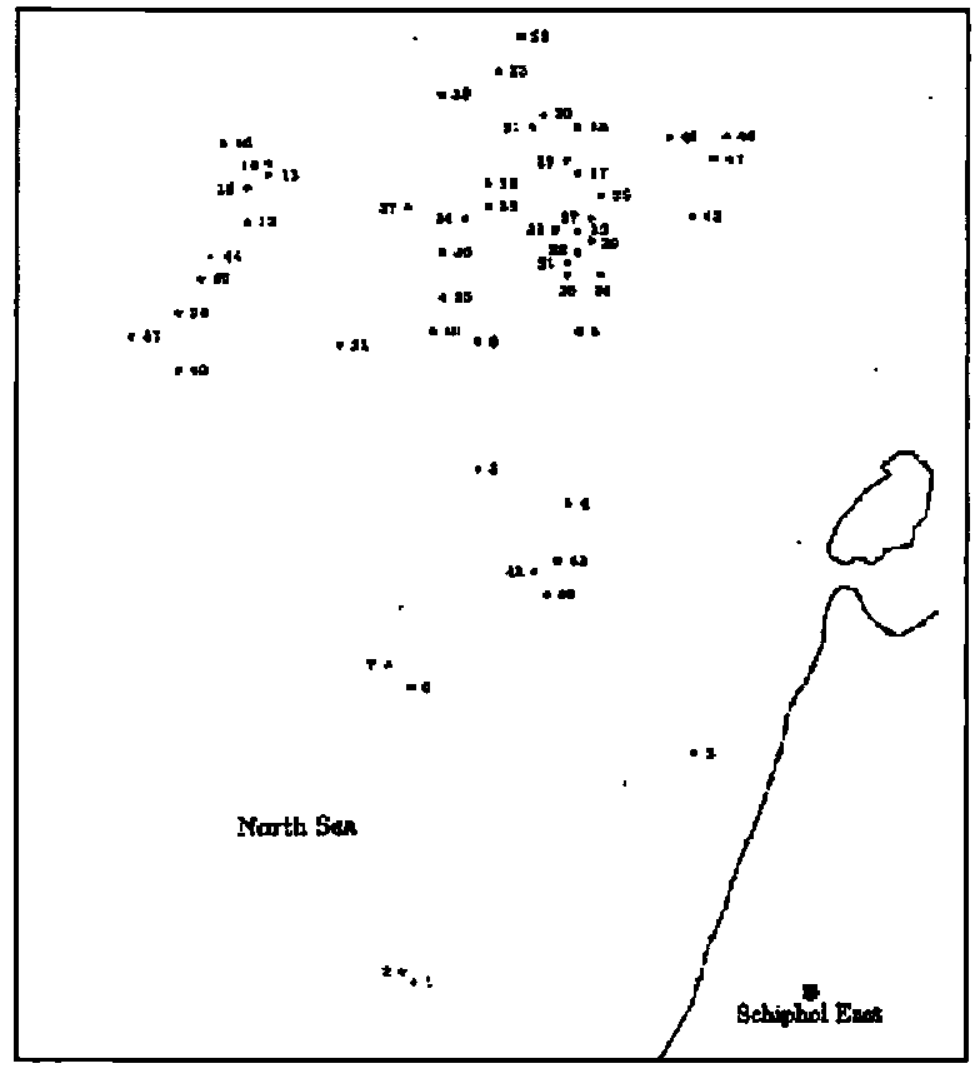

Figura 3.1: Localização Topográfica das Plataformas onde os Funcionários estão Trabalhando.

A Figura 3.2 lista as coordenadas das 51 plataformas, onde a primeira coordenada é a longitude e a segunda é a latitude. Essas coordenadas foram calculadas tendo como origem o aeroporto Schiphol.

Os helicópteros que voam da base para as plataformas levam novas pessoas e trazem as pessoas que estavam trabalhando. Desta maneira, uma pessoa que vai é sempre substituída por uma pessoa que volta. Então o número de pessoas no helicóptero durante o vôo é sempre o mesmo.

No estudo de [Sierksma \& Tijssen, 1998], o transporte dessas pessoas foi feito por helicópteros Sikorski-61, com 27 lugares (Figura 3.3). O número de helicópteros é suficiente para fazer o transporte de todas as trocas de equipes de funcionários.

O PRV consiste basicamente em definir rotas eficientes para uma frota de veículos que deve entregar quantidades de "bens" a um conjunto de clientes. Em outras palavras, este problema consiste em recobrir todos os nós de uma rede otimizando uma função objetivo. Descrevemos a seguir suas principais características, sendo que para uma melhor 


\begin{tabular}{|c|c|c|c|c|c|c|c|c|c|c|c|}
\hline Plat & \multicolumn{2}{|c|}{ Coord } & Plat & \multicolumn{2}{|c|}{ Coord } & Plat & \multicolumn{2}{|c|}{ Coord. } & Plat & \multicolumn{2}{|c|}{ Coord } \\
\hline 1 & 1 & 35 & 14 & 73 & 47 & 27 & 68 & 19 & 40 & 35 & 23 \\
\hline 2 & 2 & 236 & 15 & 71 & 49 & 28 & 65 & 20 & 41 & 37 & 24 \\
\hline 3 & 21 & 10 & 16 & 75 & 51 & 29 & 67 & 20 & 42 & 38 & 22 \\
\hline 4 & 43 & 21 & 17 & 72 & 20 & 30 & 63 & 21 & 43 & 68 & 10 \\
\hline 5 & 46 & 29 & 18 & 76 & 20 & 31 & 64 & 21 & 44 & 65 & 52 \\
\hline 6 & 27 & 35 & 19 & 73 & 21 & 32 & 67 & 22 & 45 & 63 & 53 \\
\hline 7 & 29 & 37 & 20 & 77 & 23 & 33 & 68 & 28 & 46 & 75 & 7 \\
\hline 8 & 58 & 20 & 21 & 76 & 24 & 34 & 69 & 30 & 47 & 73 & 8 \\
\hline 9 & 57 & 29 & 22 & 84 & 25 & 35 & 61 & 32 & 48 & 75 & 12 \\
\hline 10 & 58 & 33 & 23 & 18 & 27 & 36 & 65 & 32 & 49 & 55 & 55 \\
\hline 11 & 57 & 41 & 24 & 63 & 18 & 37 & 69 & 35 & 50 & 60 & 55 \\
\hline 12 & 68 & 49 & 25 & 70 & 18 & 38 & 71 & 28 & 51 & 58 & 59 \\
\hline 13 & 72 & 47 & 26 & 66 & 19 & 39 & 79 & 32 & & & \\
\hline
\end{tabular}

Figura 3.2: Uma unidade de distância corresponde a 4,5km.

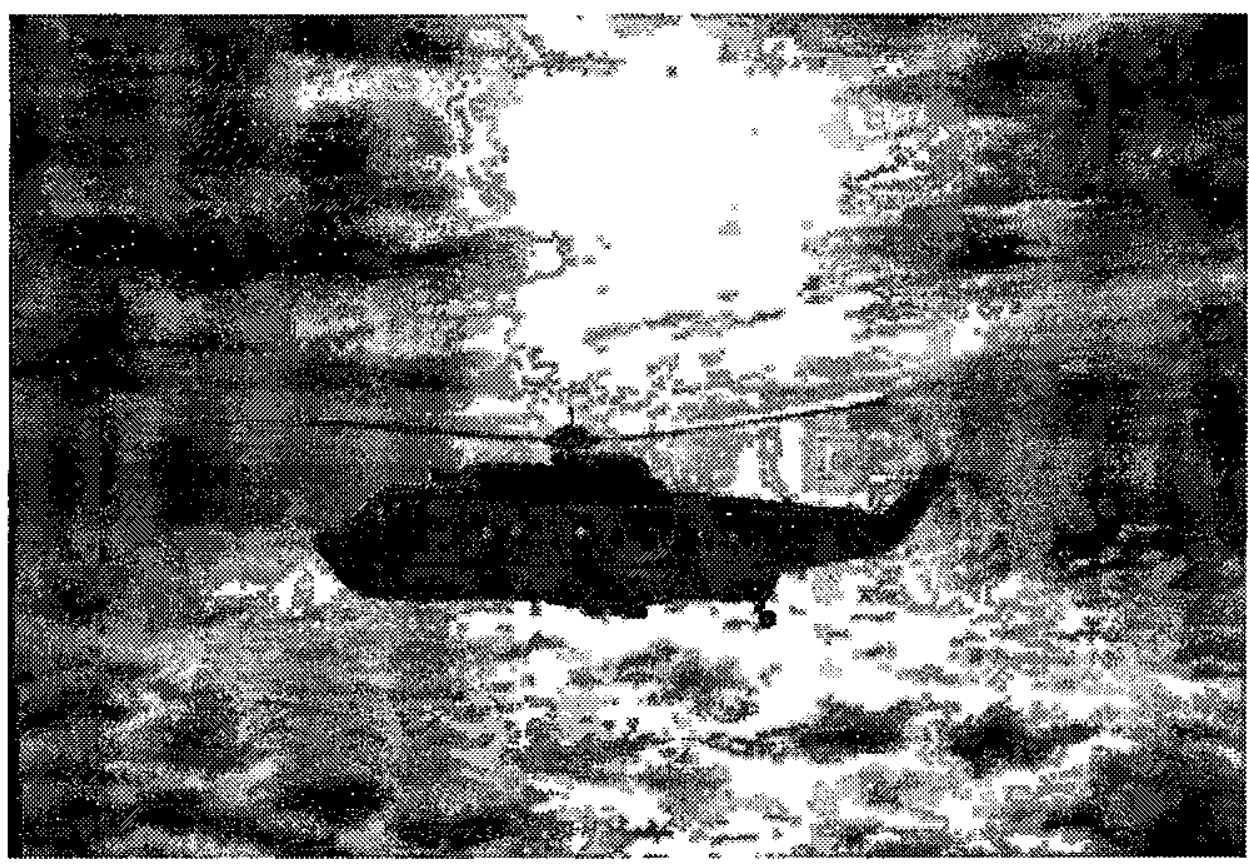

Figura 3.3: Helicóptero Sikorski-61

compreensão, especificaremos tais características relacionadas ao problema de roteamento de helicópteros, objetivo de estudo deste capítulo.

- um único depósito: o aeroporto;

- os clientes: as plataformas;

- a demanda: trocas de equipes de funcionários; 
- os veículos: os helicópteros;

- o limite de tempo de transporte: o raio de ação, chamado raio de alcance do helicóptero, determinado pela quantidade de combustível que puder ser utilizado;

- demanda dividida em partes;

- objetivo: minimizar a distância total percorrida.

Supondo que o raio de alcance seja suficiente para ir a qualquer plataforma e retornar à base, e que a capacidade do helicóptero e as demandas exigidas nas plataformas não podem ser fracionárias, ou seja, têm de ser valores inteiros, então podemos afirmar que este é um problema discreto. Começaremos com uma formulação do modelo de Programação Linear Inteira (PLI) em seguida relaxamos a condição de integralidade do problema e aplicamos a técnica de geração de colunas para resolvê-lo. A solução obtida, quando fracionária, é então arredondada para um inteiro, que geralmente não é uma solução ótima, mas é boa o suficiente.

\subsection{Modelo de Programação Linear Inteira}

Nesta seção introduziremos as variáveis e as notações que serão utilizadas para a formação matemática do problema em estudo.

$N=$ número de plataformas;

$N_{f}=$ número de vôos factíveis;

$x_{f}=$ número de vezes que o vôo $f$ é executado, $f=1, \ldots, N_{f}$;

$D_{i}=$ número de trocas de equipes de funcionários na plataforma, $i=1, \ldots, N$;

$a_{i f}=$ número de trocas de equipes de funcionários na plataforma $i$ durante o vôo $f$;

$d_{f}=$ custo de executar o vôo $f$;

$C=$ capacidade do helicóptero.

A função custo do uso de um helicóptero é uma função linear que compreende a distância total percorrida. Definimos $d_{f}$ como a distância total percorrida durante o vôo $f$, ou seja, o comprimento da menor rota partindo da base, visitando as plataformas e retornando à base (problema do caixeiro viajante).

Um vôo factível é um vôo tal que o raio de alcance $R$ do helicóptero não é ultrapassado, e o número de trocas de equipes durante o vôo não excede a capacidade $C$ 
do helicóptero. Dois vôos factíveis visitando o mesmo conjunto de plataformas, mas com diferentes trocas de equipes, são considerados como diferentes vôos factíveis.

Observe que, dado um conjunto de plataformas a serem visitadas pelo vôo $f$, existem várias possibilidades de vôos factíveis, mas a menor rota será determinada. Assim, associado ao vetor $\left(a_{1 f}, a_{2 f}, \ldots, a_{N f}\right)^{T}$ temos também a seqüência de como as plataformas foram visitadas.

O número $N_{f}$, que representa todos os vôos factíveis, cresce exponencialmente com o número de plataformas e a capacidade do helicóptero. O modelo de Programação Linear Inteira (PLI) é formulado:

$$
\begin{aligned}
\text { Minimizar } & \sum_{f=1}^{N_{f}} d_{f} x_{f} \\
\text { Sujeito } a: & \sum_{f=1}^{N_{f}} a_{i f} x_{f}=D_{i} \quad i=1, \ldots, N \\
& x_{f} \geq 0 \text { e inteiro } \quad f=1, \ldots, N_{f}
\end{aligned}
$$

A função objetivo é a distância total percorrida, onde $d_{f} x_{f}$ é o comprimento total usando o vôo $f$. O número total de passageiros nos helicópteros com destino à plataforma $i$ tem que ser igual à demanda $D_{i}$. A matriz $A=\left\{a_{i f}\right\}$ do modelo tem $N$ linhas e $N_{f}$ colunas, e contém a matriz identidade $\left(I_{N}\right)$, uma vez que existe um vôo factível que visita uma única plataforma e faz uma única troca factível (semelhante aos padrões homogêneos da seção (2.2)). Como $N_{f}$ é geralmente muito grande, o Método Simplex não pode ser aplicado na relaxação do modelo (3.1), assim a técnica de geração de colunas é um procedimento mais adequado. Relaxando a condição de integralidade do modelo anterior, temos um problema de Programação Linear (PL), o qual chamaremos Programação Linear Relaxado e denotaremos (PLR).

\subsection{Aplicação da Técnica de Geração de Colunas}

Modelos de otimização Linear com muitas colunas são resolvidos utilizando o Método de Geração de Colunas, como introduzido no capítulo 2. No caso do modelo (PLR), usaremos na $k$-ésima iteração a sub-matriz $A^{(k)}$ de $A=\left\{a_{i j}\right\}$, que será aumentada com uma ou mais colunas na próxima iteração. A coluna de $A^{(k)}$ será gerada resolvendo o Problema da Mochila juntamente com vários Problemas do Caixeiro Viajante. O procedimento de Geração de Colunas termina, digamos na iteração $l$, se todos os custos relativos 
não básicos de $A$, associados com a base ótima de $A^{(l)}$ são positivos. Isto significa que $A^{(l)}$ contém um base ótima $B$, que é a base ótima do problema (PLR).

Suponha que estamos na $k$-ésima iteração e a sub- matriz $A^{(k)}$ foi calculada. Seja $B$ uma base ótima da matriz $A^{(k)}$ do problema (PLR). Se $d_{B}$ é o vetor dos coeficientes básicos da função objetivo, então o vetor dual (multiplicador simplex) $\pi=\left(B^{-1}\right)^{T} d_{B}$ é a solução ótima dual, assim, o f-ésimo custo relativo do modelo (PLR) é dado por $d_{f}-\sum_{i=1}^{N} a_{i f} \pi_{i}$. Queremos encontrar o menor custo relativo. Então, o sub-problema de geração de colunas a seguir tem de ser resolvido:

$$
\begin{aligned}
& \text { Minimizar }\left(d_{f}-\sum_{i=1}^{N} \pi_{i} a_{i}\right) \\
& \text { Sujeito } a: \quad \sum_{i=1}^{N} a_{i} \leq C \\
& 0 \leq a_{i} \leq D_{i} \quad i=1, \ldots, N \\
& d_{f} \leq R \quad d_{f} \text { é o comprimento da menor rota } \\
& \text { do vôo } f \text { visitando as plataformas } i \\
& \left\{i t q a_{i}>0\right\}
\end{aligned}
$$

O sub-problema (3.2) determina um vetor $\left[a_{i}^{*}, \ldots, a_{N}^{*}\right]^{T}$ que representa uma coluna da matriz $A$. Note que, se a função objetivo do modelo (3.2) for negativa, então, esta não é uma coluna de $A^{(k)}$ e $B$ não é a matriz ótima do modelo (PLR).

As variáveis de decisão do sub-problema (3.2) são os $a_{i}$ 's e $d_{f}$. O sub-problema é não-linear, pois o termo $d_{f}$ depende dos valores não nulos de $a_{i}$. Definindo $S=\left\{i \mid a_{i}>0\right\}$, como o conjunto das plataformas com demandas positivas, então $d_{f}$ é definido como a menor distância da base a todas as plataformas de $S$ e voltando à base.

Logo, para resolver o sub-problema (3.2), distinguimos os seguintes procedimentos:

1. Fixado um subconjunto $S$ de plataformas, formulamos e resolvemos o Problema do Caixeiro Viajante ( $d_{f}$ é determinado) e o Problema da Mochila Resultante.

2. Geramos todos os subconjuntos $S$ de plataformas, (para cada subconjunto $S$, aplicamos o procedimento 1) descartando, se possível, todos os subconjuntos $S$ que não produzem a solução ótima de (3.2).

Fixando um subconjunto qualquer $S$, o sub-problem a (3.2) pode ser reduzido simplesmente a um Problema da Mochila, da seguinte maneira. Seja $S$ um subconjunto das $N$ plataformas e $d_{f(S)}$ a distância total percorrida durante o vôo $f(S)$ da base para as plataformas em $S$ e voltando para a base. O Problema do Caixeiro Viajante é simplesmente para determinar o comprimento da menor rota. Se o número de plataformas em 
$S$ é pequeno, este procedimento é processado muito rápido. Se o número de plataformas em $S$ é grande, serão necessários algoritmos mais elaborados. Agora, como $d_{f(S)}$ tornou uma constante, temos que analizar quando:

- $d_{f(s)}>R$, então $S$ não possui um vôo factível.

- $d_{f(S)} \leq R$, a função objetivo do sub-problema (3.2) pode ser escrita por:

$$
c(S)=d_{f(S)}-\left(\max \sum_{i \in S} a_{i} \pi_{i}\right)
$$

com $d_{f(S)}$ sendo o comprimento do menor vôo, visitando todas as plataformas $i \in S$. Assim, temos o seguinte Problema da Mochila Restrito.

$$
\begin{array}{ll}
\text { Maximizar } & \sum_{i \in S} a_{i} \pi_{i} \\
\text { Sujeito } a: & \sum_{i \in S} a_{i} \leq C \\
& 0 \leq a_{i} \leq D_{i} \text { para } i \in S
\end{array}
$$

O sub-problema (3.2) pode ser resolvido considerando sucessivamente, todos os possíveis subconjuntos $S$, e para cada subconjunto temos de resolver o Problema da Mochila. Este procedimento certamente consome muito tempo, pois o número de subconjuntos $S$ é $2^{N-1}$. A seguir é apresentado um procedimento para geração de subconjunto S.

\subsection{Geração de sub-conjuntos de plataformas}

Primeiro todas as plataformas são renumeradas tal que: $\pi_{1} \geq \pi_{2} \geq \ldots \geq \pi_{n}$. Fixando essa ordem durante o passo de geração de colunas, não é necessário a reordenação dos $\pi_{i}$ 's para cada sub-conjunto $S$ de plataformas quando resolvemos o problema da mochila. Além disso, todos os sub-conjuntos de plataformas $S$ são gerados em ordem lexicográfica. Observamos que as plataformas $P_{1}, \ldots, P_{n}$ correspondem respectivamente a $\pi_{1}, \ldots, \pi_{n}$ e que os sub-conjuntos que têm os menores índices na ordem lexicográfica, têm os maiores valores duais e, então, são gerados primeiro. Chamamos um sub-conjunto de plataformas $S_{2}$ de uma expansão lexicográfica ou simplesmente expansão, do conjunto de plataformas $S_{1}$ quando: 
- $S_{1} \subset S_{2}$ e $S_{1} \neq S_{2}$

- os índices das plataformas em $S_{2} \backslash S_{1}$ são maiores do que o maior índice das plataformas em $S_{1}$.

Assim $S_{2}$ é gerado depois de $S_{1}$, quando adicionamos uma ou mais plataformas em $S_{1}$. Por exemplo: o conjunto de plataformas $S_{2}=\left\{P_{1}, P_{2}, P_{3}\right\}$ é uma expansão do conjunto de plataformas $S_{1}=\left\{P_{1}\right\}$ mas não é uma expansão do conjunto de plataformas $S_{3}=\left\{P_{2}\right\}$. Descrevemos em seguida três critérios que possibilitam a exclusão de um sub-conjunto de plataformas $S$ e todas as suas expansões, consideradas na solução do problema da mochila.

1. Raio de alcance $R$ excedido.

Se um sub-conjunto $S$ de plataformas satisfazer: $d_{f(S)}>R$, então $S$ e suas expansões são descartados sem perda de generalidade.

2. Capacidade excedida.

Suponha que o conjunto $S$ seja um subconjunto próprio de $P$, isto é, $S \neq P$. Se $\sum_{i \in S} D_{i} \geq C$ então toda expansão de $S$ será excluída quando resolvemos o problema da mochila. A razão é que, quando adicionamos uma nova plataforma, por exemplo: $P_{t}$, no conjunto $\mathrm{S}$, temos $a_{t}^{*}=0$, isso ocorre porque o valor dual de $\pi_{t}$ é menor que todos $\pi_{i}$ 's com $i \in S$. Por excluir tais expansões de $S$, temos a vantagem de tratar somente com sub-conjuntos $S$ que possivelmente terão os $a_{t}^{*}$ 's estritamente positivos. Então, o problema do caixeiro viajante para esses sub-conjuntos visita somente plataformas com trocas de equipes positiva.

3. Limitante inferior excedido.

Se para o sub-conjunto de plataformas $S$, o valor do custo relativo $c(S)=d_{f(s)}-$ $\sum_{i \in S} \pi_{i} a_{i}^{*}$ é calculado, e $\sum_{i \in S} a_{i}^{*}<C$ então o sub-conjunto $S$ poderá ser estendido adicionando-se uma ou mais plataformas em $S$. Para encontrar alguma expansão de $S$ fornecendo uma solução melhor para o modelo (3.2) e uma solução melhor encontrada até então, um limitante inferior para o modelo (3.2) é calculado para todas as expansões de S. Seja $P_{k}$ a plataforma com o maior índice em $S$. Qualquer expansão de S consiste da união de S com um sub-conjunto de plataformas de $\left\{P_{K+1}\right.$, $\left.\ldots, P_{n}\right\}$. Note que para qualquer expansão $S^{\prime}$ de $S$, a desigualdade $d_{f\left(S^{\prime}\right)} \geq d_{f(S)}$ é satisfeita, uma viagem que visita mais plataformas. Baseado na ordenação de 
plataformas $\left(\pi_{i} \leq \pi_{k}\right.$ para $\left.i>k\right)$, temos que:

$$
\begin{aligned}
c\left(S^{\prime}\right) & \geq \min \left\{d_{f(S)}-\sum_{i \in S} \pi_{i} a_{i}-\sum_{i>k} \pi_{i} a_{i} \mid \sum_{i \in S} a_{i}+\sum_{i>k} a_{i} \leq C ; 0 \leq a_{i} \leq D_{i}\right\} \\
& =d_{f(S)}-\max \left\{\sum_{i \in S} \pi_{i} a_{i}+\sum_{i>k} \pi_{i} a_{i} \mid \sum_{i \in S} a_{i}+\sum_{i>k} a_{i} \leq C ; 0 \leq a_{i} \leq D_{i}\right\} \\
& =d_{f(S)}-\sum_{i \in S} \pi_{i} a_{i}^{*}-\max \left\{\sum_{i>k} \pi_{i} a_{i} \mid \sum_{i>k} a_{i} \leq C-\sum_{i \in S} a_{i}^{*} ; 0 \leq a_{i} \leq D_{i}\right\} \\
& =c(S)-\max \left\{\sum_{i>k} \pi_{i} a_{i} \mid \sum_{i>k} a_{i} \leq C-\sum_{i \in S} a_{i}^{*} ; 0 \leq a_{i} \leq D_{i} ; \text { para } i>k\right\}
\end{aligned}
$$

O último termo contém o problema da mochila que pode ser resolvido facilmente por ser uma mochila de tamanho reduzido. Se o limitante inferior para $c\left(S^{\prime}\right)$ for maior do que o melhor valor já encontrado da função objetivo de (3.2), então qualquer expansão de $S$ poderá ser descartada de considerações futuras sem perda de generalidade.

\subsection{Algoritmo Simplex com Geração de Colunas}

Seja $J_{k}$ o conjunto de índices de vôos correspondentes às colunas de $A^{(k)}$.

Passo 0: Inicialização: Seja $A^{(1)}=\left\{a_{i j}\right\}$ a matriz diagonal com $a_{i i}=\min \left\{D_{i}, C i=\right.$ $1, \ldots, N\}$. Calcule $d_{f}$ para cada $f \in J_{1}=\{1,2, \ldots, N\}$.

Passo 1: Resolva o Problema de Otimização Linear:

$$
\begin{array}{ll}
\text { Minimizar } & \sum_{f \in J_{k}} d_{f} x_{f} \\
\text { Sujeito a }: & \sum_{f \in J_{k}}^{(k)} a_{i j}^{(k)} x_{f}=D_{i} i=1, \ldots, N \\
& x_{f} \geq 0 \text { para } f \in J_{k}
\end{array}
$$

Seja $\pi^{(k)}=\left[\pi_{1}^{(k)}, \ldots, \pi_{N}^{(k)}\right]^{T}$ o vetor dual (multiplicador simplex).

Passo 2: Geração de Colunas

Passo 2.1: Determinar os sub-conjuntos $S$ de plataformas.

Passo 2.2: Determinar $d_{f(S)}$ resolvendo o Problema do Caixeiro Viajante. Resolvendo o Problema da Mochila, teremos determinado

$$
c(S)=d_{f(S)}-\sum_{i \in S} \pi_{i} a_{i}^{*}
$$


Se $c(S)$ é o melhor valor da função objetivo do sub-problema (3.2), salve a solução correspondente como $a^{*}$ (e $S^{*}$ os índices das plataformas).

Passo 2.3: Se $c\left(S^{*}\right) \geq 0$, então PARE, solução ótima encontrada.

Se $c\left(S^{*}\right)<0$, então defina

$$
\begin{gathered}
A^{(k+1)} \equiv\left[A^{(k)}, a^{*}\right], \\
J_{k+1}=J_{k} \cup\{N+k\}, k=k+1 .
\end{gathered}
$$

e volte para o passo 1 , onde $a^{*}$ é a $(\mathrm{N}+\mathrm{k})$-ésima coluna de $A^{k+1}$.

\subsection{Procedimento de Arredondamento para determi- nação de solução inteira}

O Método Simplex, em geral, produz soluções fracionária. Uma solução inteira pode ser obtida por meio de um procedimento de arredondamento, maiores detalhes podem serem encontrados em [Sierksma \& Tijssen, 1998]. Assim, temos a seguir o algoritmo para produzir soluções inteiras.

Algoritmo de Arredondamento:

A cada iteração deste algoritmo, o vetor-demanda $\left[D_{1}, \ldots, D_{N}\right]^{T}$ do problema (PLR) é atualizado. Considere $d$ sendo o vetor atual do (PLR), denotado por (PLR/d).

Passo 0: Inicialize $d=\left[D_{1}, D_{2}, \ldots, D_{N}\right]^{T}$.

Passo 1: Resolva o modelo (PLR/d) através do Método Simplex com Geração de Coluna. Se a solução de (PLR/d) for inteira PARE.

Senão vá para o Passo 2.

Passo 2: Escolha uma variável aleatoriamente do modelo (PLR/d) com um valor positivo,

digamos $x_{f}>0$. Se $x_{f} \leq 1$, tome $x_{f}=\left\lceil x_{f}\right\rceil=1$, e se $x_{f}>1$, tome $x_{f}=\left\lfloor x_{f}\right\rfloor$.

O vôo $f$ é realizado $\left\lceil x_{f}\right\rceil$ ou $\left\lfloor x_{f}\right\rfloor$ vezes.

Atualização: $d_{i} \leftarrow d_{i}-a_{i f} x_{f}, i=1, \ldots, n$. Se $d=0$, então PARE.

Senão, vá para o Passo 3. 
Passo 3: Remova todas as colunas de $A$ que não correspondam mais aos vôos viáveis.

Estas são as colunas nas quais existem um $a_{i f}$ que é maior do que o atual $d_{i}$ correspondente. Além disso, estenda $A$ com a matriz diagonal $Q_{d}$ onde $q_{i i}=\min \left\{d_{i}, C\right\}$ na sua principal diagonal a fim de garantir a viabilidade do modelo.

Retorne ao Passol.

Observe que no Passo 2, o valor da variável é fixado em um valor inteiro positivo. Se a variável tem um valor menor do que um, é arredondado superiormente, ou seja, para 1. Se a variável tem um valor maior do que um, é arredondado inferiormente. Pode parecer um pouco surpreendente que o valor não inteiro 1.95 é arredondado inferiormente para 1, ao invés de ser arredondado superiormente para 2, pois poderá introduzir uma inviabilidade no problema, de modo que mais membros das equipes sejam trocados do que estejam disponíveis. Arredondando inferiormente deixa-se aberta a possibilidade de que em uma outra iteração subseqüente um vôo é selecionado quase idêntico ao anterior, mas, com poucos lugares não ocupados.

\subsection{Considerações Finais}

[Sierksma \& Tijssen, 1998] apresentam resultados computacionais com no máximo 151 plataformas marítimas. O número de trocas de equipes de funcionários é o número de funcionários que trabalham nas plataformas e têm de ser trocados uma vez por semana. Este número sofre uma variação de 2 a 50. Por isso, geralmente, uma plataforma tem de ser visitada por 2 ou mais helicópteros.

As viagens geradas pelos caixeiros viajantes dificilmente possuem mais do que 5 plataformas, por isso, não é necessário usar métodos avançados para construção destas viagens, pois uma simples enumeração é suficiente.

Para evitar que a mesma viagem fosse calculada várias vezes, os autores mantiveram uma lista de viagens, junto com suas distâncias e o conjunto de plataformas que elas visitam. Quando foi necessário calcular o menor caminho do caixeiro viajante para um certo conjunto de plataformas, foi verificado primeiro nas listas se a viagem já havia sido calculada, senão é calculada e adicionada na lista. 


\section{Capítulo 4}

\section{Us da Técnica de Geração de Colunas em Problemas de Roteamento com Janela de Tempo}

\subsection{Considerações Iniciais}

Neste capítulo abordamos o trabalho desenvolvido por [Desrosiers et al., 1984] com o propósito de apresentarmos um método baseado na técnica de geração de colunas que resolve otimamente o problema de rotas com janela de tempo. O objetivo é minimizar o custo total do transporte. Este problema é uma generalização do Problema $m$-Caixeiros Viajantes e pode ser formulado como um Problema de Partição de Conjuntos e resolvido através da técnica de geração de colunas, onde as colunas são geradas pela resolução do problema do caminho mínimo com janela de tempo.

\subsection{Descrição e Formulação do Problema}

Considere um conjunto de viagens, onde cada viagem $i$ é especificada por um intervalo de tempo $\left[a_{i}, b_{i}\right]$, no qual a viagem deve ser iniciada, cuja representação gráfica corresponde a um nó de uma rede. Uma viagem é uma "jornada produtiva". Definimos inter-viagem ou viagem de conexão como sendo uma "jornada não-produtiva" conduzida por um veículo. Desta maneira, uma inter-viagem é representada pelo arco $(i, j)$ que vai do final da viagem $i$ para o início da viagem $j$. A cada inter-viagem ( $i, j$ ) associamos um tempo de duração dado por $t_{i j}$ e um custo dado por $c_{i j}$. Uma rota é uma seqüência de viagens e inter-viagens conduzida pelo mesmo veículo. Considere $P$ como sendo o conjunto das viagens e $I$ o conjunto das inter-viagens. Uma inter-viagem é considerada 
se e somente se for possível realizar a viagem $j$ depois da viagem $i$, onde a restrição de intervalo de tempo $\left(a_{i}+t_{i j} \leq b_{j}\right)$ é respeitada.

Descrevemos o problema com um único depósito, onde cada veículo sai do depósito uma única vez. Os nós $s$ e $t$ representam a saída e a entrada para o depósito, respectivamente. Como o depósito é único, $s$ e $t$ coincidem, porém são representados separadamente para que haja uma melhor compreensão da rede. A rede usada pelos veículos é definida por um conjunto de nós $N=P \cup\{s, t\}$ e um conjunto de arcos orientados dado por $A=I \cup(\{s\} \times P) \cup(P \times\{t\})$.

A seguir representamos graficamente uma rede formada por 6 viagens (nós) e um conjunto de arcos orientados, com o objetivo de ilustrar a rede $(N, A)$, (veja figura 4.1).

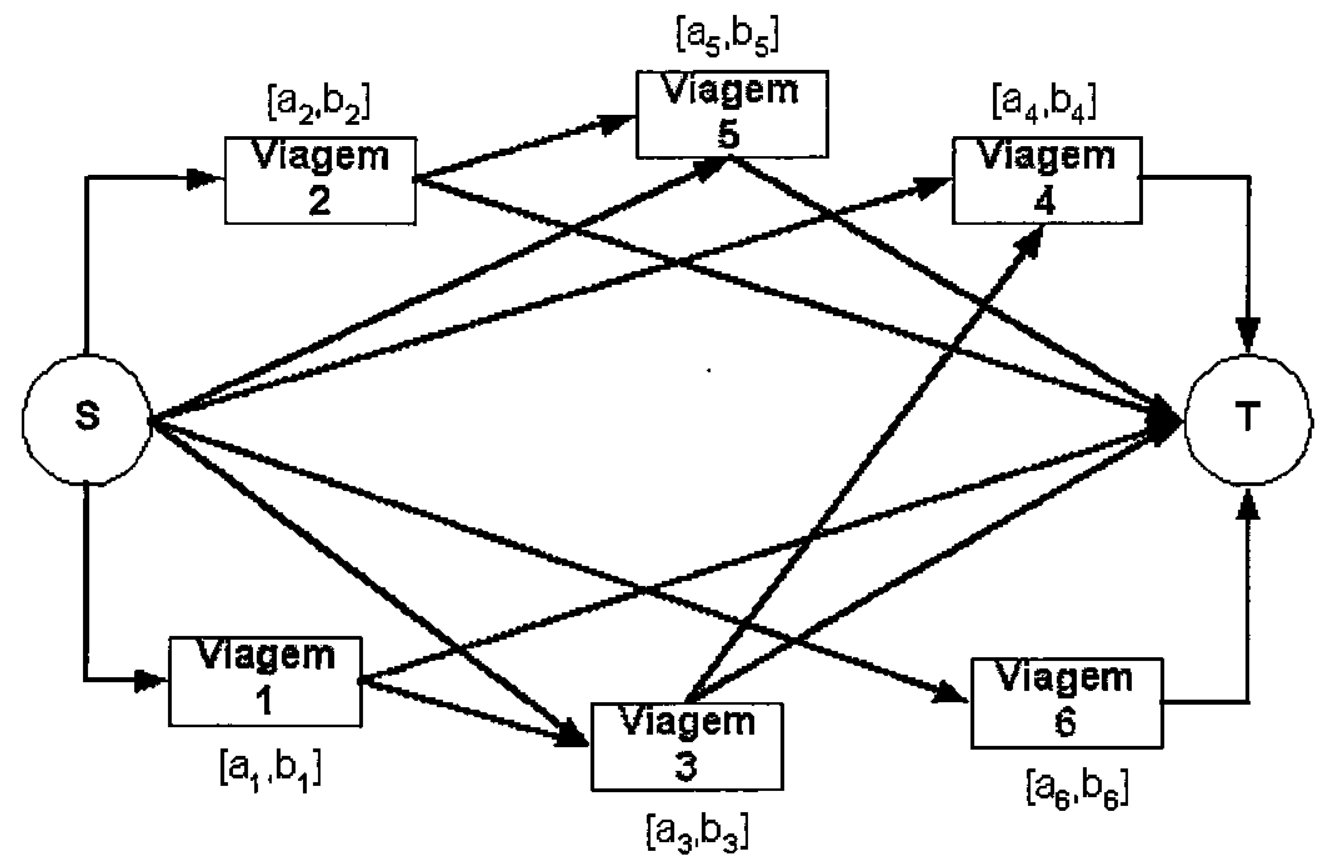

Figura 4.1: Exemplo de uma rede formada por 6 viagens (nós)

As variáveis a serem usadas na formulação do problema são dadas por:

- $x_{i j}=\left\{\begin{array}{ll}1 & \text { se o arco }(i, j) \text { for usado por um veículo } \\ 0 & \text { caso contrário. }\end{array}\right.$, onde $(i, j) \in A$

- $t_{i}$ : variável que representa o tempo associado ao início de cada viagem $i$, com $i \in P$.

Desta maneira, rotas ótimas que respeitam as restrições de horários são as soluçōes do seguinte problema: 
Minimizar $\sum_{(i, j) \in A} c_{i j} x_{i j}$

Sujeito a :

$$
\begin{array}{lr}
\sum_{j \in \mathbb{N}} x_{j i}=1 ; \sum_{i \in \mathbb{N}} & i \in P \\
\sum_{k \in \mathbb{N}} x_{i k}=1 ; & i \in P \\
x_{i j} \geq 0 ; & (i, j) \in A \\
x_{i j}>0 \Rightarrow t_{i}+t_{i j} \leq t_{j} ; & (i, j) \in I \\
a_{i} \leq t_{i} \leq b_{i} ; & i \in P \\
x_{i j}=\{0 ; \overline{1}\} & (i, j) \in A
\end{array}
$$

As restrições (4.1) informam que de exatamente um único nó $j$, o veículo chegará ao nó $i$. As restrições (4.2) afirmam que o veículo que chegou ao nó $i$ vai ter que partir para exatamente um único nó $j$. As restrições (4.4) descrevem a compatibilidade requerida entre as rotas e os horários e as restrições (4.5) estabelecem o intervalo de tempo no qual a viagem deve ser inciada.

Observe que a restrição (4.4) não é restrição lógica e pode ser escrita pela seguinte forma linear:

$$
t_{i}+t_{i j}-t_{j} \leq\left(1-x_{i j}\right) M_{i j}, \quad \text { com }(i, j) \in I \text { e } M_{i j} \geq b_{i}+t_{i j}-a_{j} .
$$

Esta formulação exige que a variável $x_{i j}$ seja inteira. Se relaxarmos a integralidade da variável $x_{i j}$, ou seja, $0<x_{i j}<1$, teremos a seguinte equação:

$$
0<t_{i}+t_{i j}+t_{j} \leq\left(1-x_{i j}\right) M_{i j}
$$

No entanto, a equação (4.8) não satisfaz a restrição (4.4) do problema inicial. Portanto a variável $x_{i j}$ tem que ser inteira.

\subsection{Formulação por Partição de Conjuntos}

Nesta seção introduziremos a notação usada para a formulação do Problema de Partição de Conjunto e discutiremos a relaxação feita por programação linear que será 
resolvida utilizando o método de geração de colunas. Consideremos então a seguinte notação:

$\Omega=$ conjunto das rotas com os horários satisfazendo as restrições (4.4) e (4.5);

$y_{r}= \begin{cases}1 & \text { se a rota } r \text { é usada } \\ 0 & \text { caso contrário }\end{cases}$

$\delta_{r i}= \begin{cases}1 & \text { se na rota } r \text { inclui a viagem } i \\ 0 & \text { caso contrário }\end{cases}$

$c_{r}$ : custo da rota $r$ : a soma dos custos dos arcos percorridos pela rota mais o custo fixo por veículo.

O processo de solução consiste em construir um conjunto de rotas com o menor custo, satisfazendo as restrições de horários e incluindo cada viagem exatamente uma vez. O problema-mestre, que define o conjunto ótimo de rotas é formulado como um problema de partição de conjunto dado por:

$$
\begin{array}{lll}
\text { Minimizar } & \sum_{r \in \Omega} c_{r} y_{r} & \\
\text { sujeito } a: & \sum_{r \in \Omega} \delta_{r i} y_{r}=1, & i \in P \\
& y_{r}=\{0,1\}, & r \in \Omega
\end{array}
$$

Devido ao grande número de rotas em $\Omega$, a relaxação por Programação Linear do problema de partição de conjuntos é resolvido por geração de coluna. Uma nova coluna com o menor custo relativo é gerada, resolvendo-se o problema de caminho mínimo com restrição de horário. Em seguida, resumidamente, mostramos como obter o problema de carninho mínimo.

O menor custo relativo, resume-se em resolver o seguinte sub-problema:

$$
c_{r}-\pi^{t} \delta_{r}=\min \left\{c_{r}-\sum_{i} \pi_{i} \delta_{r i}, \quad r \in \Omega\right\}
$$

Sem perda de generalidade, tomemos $\delta$ como sendo uma coluna de $A$, então, temos:

$$
\delta_{i}=\sum_{j \in P} x_{i j} \text { e } \delta=\left(\delta_{1}, \ldots, \delta_{i}, \ldots, \delta_{N}\right)
$$

e seu coeficiente na função-objetivo é dado por:

$$
C(\delta)=\sum_{(i, j) \in A} c_{i j} x_{i j}
$$


O custo relativo da variável cuja coluna é dada por $\delta$, é determinado por $\varphi(\delta)=$ $C(\delta)-\pi^{t} \delta_{r}$. Então, temos:

$$
\begin{aligned}
\varphi(\delta) & =C(\delta)-\pi^{t} \delta \\
& =\sum_{(i, j) \in A} c_{i j} x_{i j}-\sum_{i} \pi_{i} \sum_{j \in P} x_{i j} \\
& =\sum_{(i, j) \in A} c_{i j} x_{i j}-\sum_{(i, j) \in A} \pi_{i} x_{i j} \\
& =\sum_{(i, j) \in A}\left(c_{i j}-\pi_{i}\right) x_{i j}
\end{aligned}
$$

Assim, o sub-problema para determinarmos a coluna de $A$ para entrar na base, é dado por:

$$
\operatorname{Minimizar} \varphi(\delta)=\sum_{(i, j) \in A}\left(c_{i j}-\pi_{i}\right) x_{i j}
$$

onde as variáveis binárias devem definir um caminho de $s$ a $t$, respeitando as janelas de tempo, ou seja:

$$
\begin{aligned}
& \text { Minimizar } \sum_{(i, j) \in A}\left(c_{i j}-\pi_{i}\right) x_{i j} \\
& \text { sujeito } a: \sum_{j \in \mathbb{N}} x_{i j}=\sum_{j \in N} x_{j i} \quad i \in P \\
& \sum_{j \in P} x_{s j}=1 \\
& \sum_{j \in P} x_{j t}=1 \\
& x_{i j}>0 \Rightarrow t_{i}+t_{i j} \leq t_{j} \\
& a_{i} \leq t_{i} \leq b_{i} \\
& (i, j) \in I \\
& x_{i j}=\{0,1\} \\
& i \in P \\
& (i, j) \in A
\end{aligned}
$$

As restrições (4.14) garantem a conservação de fluxo, ou seja, se o veículo entrou no nó $i$, ele tem de sair deste nó $i$ para algum outro. As restrições (4.15) afirmam que o veículo sai do depósito $s$ para algum nó $j$. As restrições (4.16) garantem que o veículo chega de algum nó $j$ no depósito $t$. Essas três restrições formam juntas as condições necessárias para a existência da rota. As três últimas restrições são as restrições de horários, que já foram comentadas no modelo anterior. 


\subsection{Solução do sub-problema}

A rota de custo mínimo, satisfazendo as restrições de horário, chamada de Caminho Mínimo Com Janela de Tempo (CMJT) é encontrada usando uma adaptação do algoritmo Ford-Bellman conhecido como Caminho Mínimo Com Janela de Tempo (CMJT).

O algoritmo Ford-Bellman determina para cada nó uma etiqueta $\theta_{i}$ representando o custo do caminho de ir da origem $s$ para o destino $i$. Para problemas de caminho mínimo com restrição de horário, as rotas têm de ser comparadas em termos de seu tempo de chegadas até os nós. Desta forma, o algoritmo CMJT requer um par de etiquetas para cada nó (tempo de chegada ao nó $i$, custo da rota). Várias etiquetas devem ser armazenados no nó $i$, pois estes podem ser utilizados para calcularmos rótulos de outros nós.

\subsection{Solução do Problema-Mestre}

O algoritmo simplex é usado para solucionar a relaxação linear do problemar mestre. Este método fornece os multiplicadores simplex $\pi_{i}$ necessários para geração de cada coluna e possibilita uma fácil reotimização das novas colunas cada vez que são solicitadas.

A figura 4.2 mostra a iteração incluindo a geração de rotas com horários, seguida pela reotimização do problema de cobertura. Experiências iniciais realizadas por [Desrosiers et al., 1984] mostraram que o maior tempo computacional é usado pelo algoritmo Simplex, enquanto que o algoritmo CMJT leva pouco tempo. O procedimento pode ser modificado para acelerar a convergência, gerando várias rotas em cada iteração. Esta modificação explora a idéia de que é útil incluir no conjunto $\Omega^{\prime}\left(\Omega^{\prime} \subseteq \Omega\right)$ conjuntos das rotas geradas com a probabilidade de reduzir a função objetivo.

As rotas alternativas com custos relativos negativos são disjuntas, isto é, nós (viagens) cobertos por rotas anteriores serão desconsiderados na determinação dos demais.

A construção de rotas disjuntas favorecem o aparecimento de soluções inteiras. Esta estratégia considerada reduz o número de iteração de modo que o tempo computacional é reduzido significativamente. 


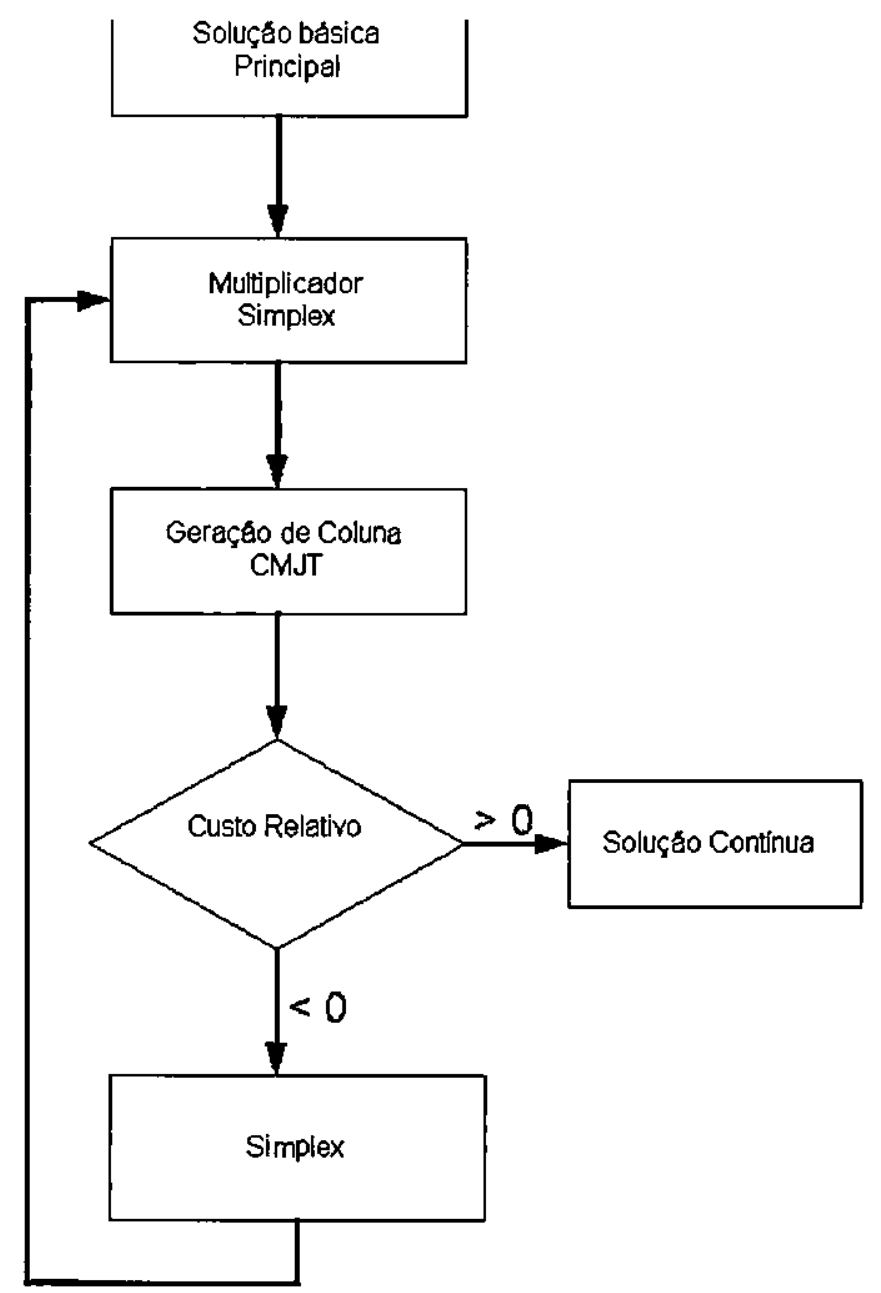

Figura 4.2: Método Simplex com Geração de coluna

\subsection{Obtenção de solução inteira}

A Obtenção de uma solução inteira para o problema-mestre, usando o método simplex é uma tarefa muito difícil. A geração de uma solução inteira é obtida usando um plano de corte referente ao número de veículos e ao custo da viagem, que é arredondado superiormente para o próximo inteiro. Quando a solução não for inteira, somente poucas variáveis fracionárias restarão para serem eliminadas. Isto pode-se feito por um processo de Enumeração Implícita usando geração de colunas para resolver o problema em cada nó da árvore. 


\subsubsection{O Plano de Corte}

A função objetivo (4.20) está separada em dois termos: o custo fixo associado ao número de veículos e o custo da viagem.

$$
C\left(\sum_{j \in P} x_{s j}\right)+\sum_{(i, j) \in I} c_{i j} x_{i j}
$$

Estudos de casos revelam que o custo $\mathrm{C}$ é suficientemente grande, de modo que não é conveniente aumentar o número de veículos para reduzir o custo da viagem (percurso). Assim, a primeira solução ótima que minimize o número de veículos também minimizará 0 custo da viagem.

Quando o número de veículos na solução ótima do problema mestre for fracionário, um plano de corte é adicionado para que este número seja arredondado para o próximo inteiro fazendo com que o problema-mestre seja então reotimizado gerando novas colunas.

\subsubsection{A Ramificação}

A ramificação em um nó ocorre quando a variável associada à rota é fracionária. Um detalhe importante é que neste procedimento não fixamos as variáveis $y_{r}$ do problema de partição de conjunto, mas sim, as variáveis $x_{i j}$ associadas aos arcos que correspondem à rota $r$, são fixadas em zero ou um.

Para compreendermos este processo de ramificação, revisaremos o modelo do problema de partição de conjunto descrito na seção (4.3).

$$
\begin{aligned}
& \text { Minimizar } \sum_{r \in \Omega} c_{\tau} y_{r} \\
& \text { Sujeito } a: \sum_{r \in \Omega} \delta_{r i} y_{r}=1 \quad i \in P \\
& y_{r} \in\{0,1\}
\end{aligned}
$$

e sua relaxação linear:

$$
\begin{array}{cl}
\text { Minimizar } & \sum_{r \in \Omega} c_{r} y_{r} \\
\text { Sujeito } a: & \sum_{r \in \Omega} \delta_{r i} y_{r}=1 \quad i \in P \\
& 0 \leq y_{r} \leq 1
\end{array}
$$

Considere que o vetor $y=\left(y_{1}, y_{2}, \ldots, y_{n}\right)$ seja uma solução para o problema relaxado. Tomamos sem perda de generalidades, que $y_{1}$ seja fracionária; logo o processo de ramificação tem de ser aplicado, ou seja, $y_{1}$ deverá ser fixada em 1 ou 0. 
Se fixarmos $y_{1}=1$ estamos afirmando que a rota $\delta_{i 1}$ está sendo utilizada e, consequentemente, os arcos que compõem esta rota estão sendo visitados, e portanto, recebem o valor 1 .

Explicaremos este processo de ramificação através de um exemplo de uma pequena rede formada por 5 nós, um ponto de origem e um destino. Tomamos uma rota $r$ formada por: $r=$ origem $-2-4-$ destino

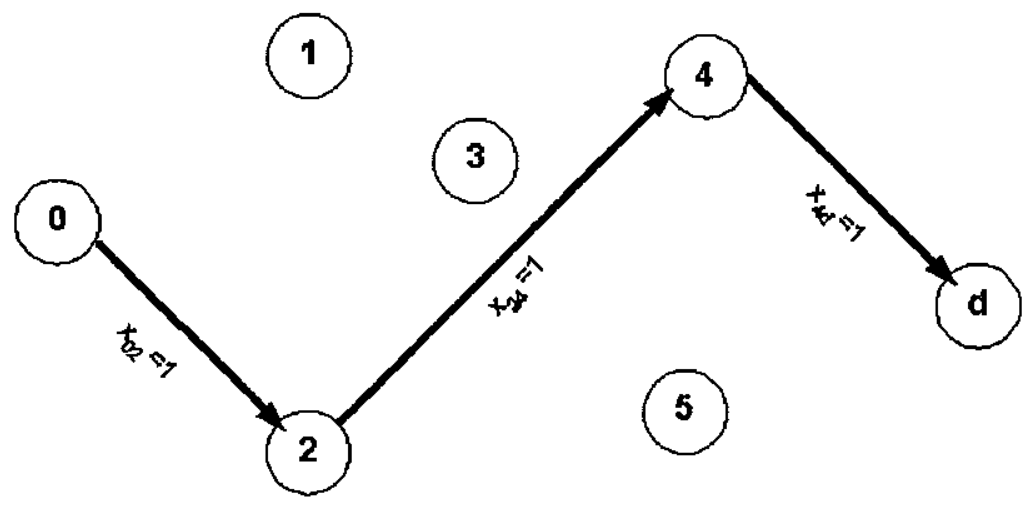

Figura 4.3: Representação da rota $r$

A rota $r$ corresponde a uma coluna do problema, assim $\delta_{i 1}=\left[\begin{array}{lllll}0 & 1 & 0 & 1 & 0\end{array}\right]^{T}$; com os $\operatorname{arcos} x_{02}=x_{24}=x_{4 d}=1$.

Resolvemos para este caso, um problema com menos variáveis, ou seja:

$$
\begin{aligned}
\text { Minimizar } & \sum_{r \in \Omega} c_{r} y_{r} \\
\text { Sujeito } a: & \sum_{r \in \Omega} \delta_{r i} y_{r}=1 \quad i \in P \\
& 0 \leq y_{r} \leq 1 \\
& x_{02}=x_{24}=x_{4 d}=1
\end{aligned}
$$

Se fixarmos $y_{1}=0$ estaremos afirmando que a rota $\delta_{i 1}$ não vai ser utilizada, consequentemente a rota $r$ não será executada. Para impedir a realização desta rota $r$, basta retirar ou acrescentar um arco $x_{i j}$ na rota e esta ficará diferente da anterior. Assim várias combinações podem ser feitas para se obter rotas alternativas a esta. Então o problema a ser resolvido torna-se vários problemas, pois para cada rota temos um problema o ser resolvido respeitando a seguinte restrição: os arcos utilizados durante o percurso da rota assumirão o valor um.

Consequentemente estará diminuindo o número de variáveis do problema, tornandoo mais fácil de ser resolvido. 


\subsection{Considerações Finais}

Devido às limitações computacionais, [Desrosiers et al., 1984] utilizaram o algoritmo simplex apenas para resolver problemas com menos de 151 viagens.

Os autores observaram que em problemas com dados reais sem janela de tempo, o tamanho da frota obtida na resolução do problema quando comparada com o tamanho da frota exigida para fazer as mesmas viagens, mas com janela de tempo, poderia ser reduzido em até 50 porcento. Isso indica que a janela de tempo consiste em restrições bastante rígidas na prática.

Apresentamos a seguir um exemplo didático exibindo passo-a-passo todas as iterações do algoritmo Primal Simplex cujo o sub-problema é resolvido utilizando o algoritmo de caminho mínimo com janela de tempo. A figura 4.4 apresenta o grafo a ser resolvido durante o exemplo.

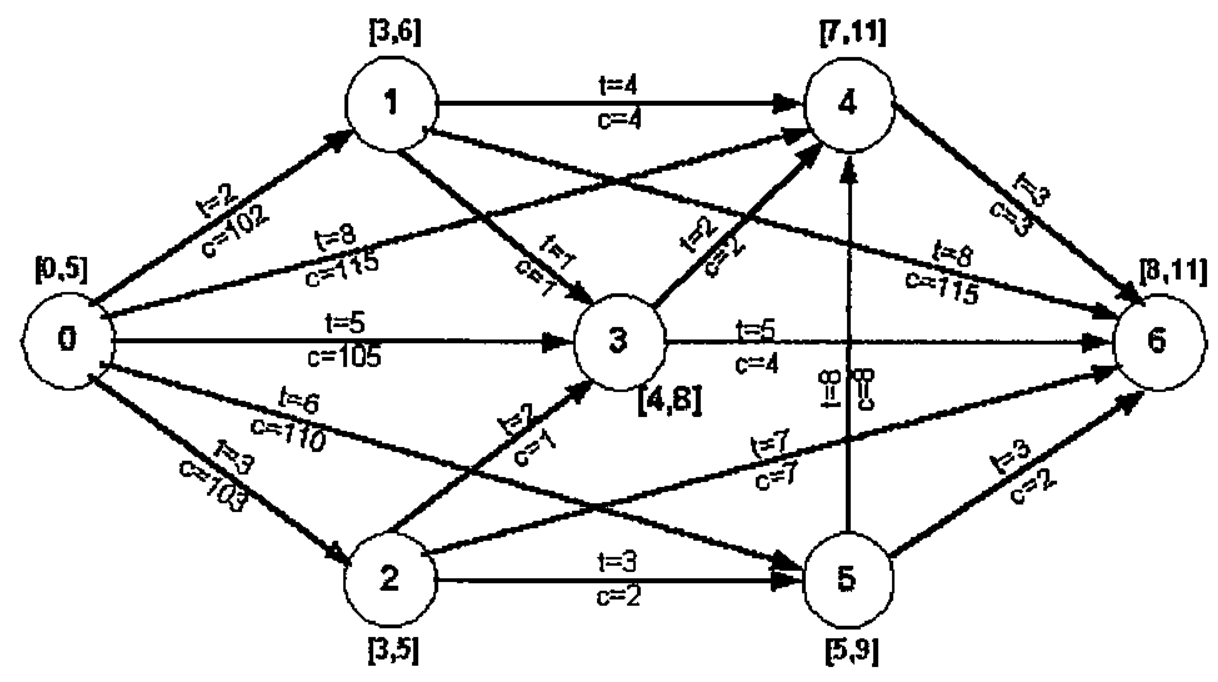

Figura 4.4: Grafo representando o problema em questão

- $1^{a}$ ITERAÇ̃̃O

$$
A=\left[\begin{array}{lllll}
1 & 0 & 0 & 0 & 0 \\
0 & 1 & 0 & 0 & 0 \\
0 & 0 & 1 & 0 & 0 \\
0 & 0 & 0 & 1 & 0 \\
0 & 0 & 0 & 0 & 1
\end{array}\right]
$$


Solução Básica:

$$
X_{B}=(1,1,1,1,1)
$$

Vetor Multiplicador Simplex:

$$
\pi=(110,110,109,118,112)
$$

Colunas Geradas associadas ao caminho mínimo:

$$
\begin{array}{ll}
\operatorname{ak}[0]=(1,0,1,1,0) & \operatorname{ak}[1]=(0,1,0,0,1) \\
\operatorname{ck}[0]=108 & \operatorname{ck}[1]=107 \\
\text { CustoRelativo[0]=-229 } & \text { CustoRelativo[1]=-115 }
\end{array}
$$

CustoMínimo $=-229$

Direção Básica:

$$
d b=(-1,0,-1,-1,0)
$$

$$
A=\left[\begin{array}{lllll}
1 & 0 & 0 & 0 & 0 \\
0 & 1 & 0 & 0 & 0 \\
1 & 0 & 1 & 0 & 0 \\
1 & 0 & 0 & 1 & 0 \\
0 & 1 & 0 & 0 & 1
\end{array}\right]
$$

$\mathrm{C}=(108,110,109,118,112)$

$X_{B}=(1,1,0,0,1)$

- $2^{a}$ ITERAÇÃO

Vetor Multiplicador Simplex:

$$
\pi=(-119,110,109,118,112)
$$

Colunas Geradas associadas ao caminho mínimo: 


$$
\begin{aligned}
& \operatorname{ak}[0]=(0,1,1,1,0) \\
& \operatorname{ck}[0]=109
\end{aligned}
$$

CustoRelativo[0] $=-228$ $\operatorname{ak}[1]=(0,1,0,0,1)$

$\operatorname{ck}[1]=107$

CustoRelativo[1] $=-115$

CustoMínimo=-228

\section{Direção Básica:}

$$
\begin{gathered}
\mathrm{db}=(0,-1,-1,-1,0) \\
A=\left[\begin{array}{lllll}
1 & 0 & 0 & 0 & 0 \\
0 & 1 & 1 & 0 & 0 \\
1 & 0 & 1 & 0 & 0 \\
1 & 0 & 1 & 1 & 0 \\
0 & 0 & 0 & 0 & 1
\end{array}\right]
\end{gathered}
$$

$\mathrm{C}=(108,110,109,118,112)$

$X_{B}=(1,1,0,0,1)$

- $3^{a} \operatorname{ITERAC\tilde {O}O}$

Vetor Multiplicador Simplex:

$$
\pi=(109,110,-119,118,112)
$$

Colunas Geradas ao caminho mínimo:

$$
\begin{array}{ll}
\operatorname{ak}[0]=(1,0,0,1,0) & \operatorname{ak}[1]=(0,1,0,1,0) \\
\operatorname{ck}[0]=109 & \operatorname{ck}[1]=107 \\
\text { CustoRelativo[0] }=-188 & \text { CustoRelativo[1]=-115 }
\end{array}
$$

CustoMínimo=-118

\section{Direção Básica:}




$$
\begin{aligned}
\mathrm{db}=(-1,1,1,-1,0) & \\
A & =\left[\begin{array}{lllll}
1 & 0 & 0 & 1 & 0 \\
0 & 1 & 1 & 0 & 0 \\
1 & 0 & 1 & 0 & 0 \\
1 & 0 & 1 & 1 & 0 \\
0 & 0 & 0 & 0 & 1
\end{array}\right]
\end{aligned}
$$

$\mathrm{C}=(108,110,109,109,112)$

$X_{B}=(1,1,0,0,1)$

- $4^{a} I T E R A C \tilde{A} O$

Vetor Multiplicador Simplex:

$$
\pi=(109,110,-1,0,112)
$$

Coluna Gerada associadas ao caminho mínimo:

$$
\begin{aligned}
& \operatorname{ak}[0]=(0,1,0,0,1) \\
& \operatorname{ck}[0]=107 \\
& \text { CustoRelativo[0]=-115 }
\end{aligned}
$$

CustoMínimo=-115

Direção Básica:

$$
\begin{gathered}
\mathrm{db}=(0,-1,0,0,-1) \\
A=\left[\begin{array}{lllll}
1 & 0 & 0 & 1 & 0 \\
0 & 1 & 1 & 0 & 0 \\
1 & 0 & 1 & 0 & 0 \\
1 & 0 & 1 & 1 & 0 \\
0 & 1 & 0 & 0 & 1
\end{array}\right]
\end{gathered}
$$


$\mathrm{C}=(108,107,109,109,112)$

$X_{B}=(1,1,0,0,0)$

- $5^{a}$ ITERAÇÃO

Vetor Multiplicador Simplex:

$$
\pi=(-6,-5,-1,115,112)
$$

Colunas Geradas associadas ao caminho mínimo:

$$
\begin{array}{ll}
\operatorname{ak}[0]=(0,0,1,1,0) & \operatorname{ak}[1]=(0,0,0,0,1) \\
\operatorname{ck}[0]=110 & \operatorname{ck}[1]=112 \\
\text { CustoRelativo[0]=-4 } & \text { CustoRelativo[1]=0 }
\end{array}
$$

CustoMínimo=-4

Direção Básica:

$$
\begin{gathered}
\mathrm{db}=(0,1,-1,0,-1) \\
A=\left[\begin{array}{lllll}
1 & 0 & 0 & 1 & 0 \\
0 & 1 & 0 & 0 & 0 \\
1 & 0 & 1 & 0 & 0 \\
1 & 0 & 1 & 1 & 0 \\
0 & 1 & 0 & 0 & 1
\end{array}\right]
\end{gathered}
$$

$\mathrm{C}=(108,107,110,109,112)$

$X_{B}=(1,1,0,0,0)$ 
- $\sigma^{a}$ ITERAÇÃO

Vetor Multiplicador Simplex:

$$
\pi=(-2,-5,-1,111,112)
$$

Colunas Geradas associadas ao caminho mínimo:

$$
\begin{array}{ll}
\operatorname{ak}[0]=(1,0,1,1,0) & \operatorname{ak}[1]=(0,1,0,0,1) \\
\operatorname{ck}[0]=112 & \operatorname{ck}[1]=107 \\
\text { CustoRelativo[0]=0 } & \text { CustoRelativo[1]=0 }
\end{array}
$$

Como os custos relativos são não negativos, pode se concluir que o método simplex encontrou em seis iterações a solução ótima para o problema, apresentada a seguir:

$$
\begin{aligned}
& \mathrm{xb}(1)=1 \\
& \mathrm{xb}(2)=1 \\
& \mathrm{xb}(3)=0 \\
& \mathrm{xb}(4)=0 \\
& \mathrm{xb}(5)=0
\end{aligned}
$$

E o valor da função objetivo é 215 . Observe que a solução encontrada é inteira e portanto, é a solução ótima para o problema de partição de conjunto (se a solução não fosse inteira, seria necessário uma heurística de arredondamento para obter a solução inteira). A figura 4.5 mostra os caminhos ótimos (colunas geradas) passando por todos os nós da rede. 


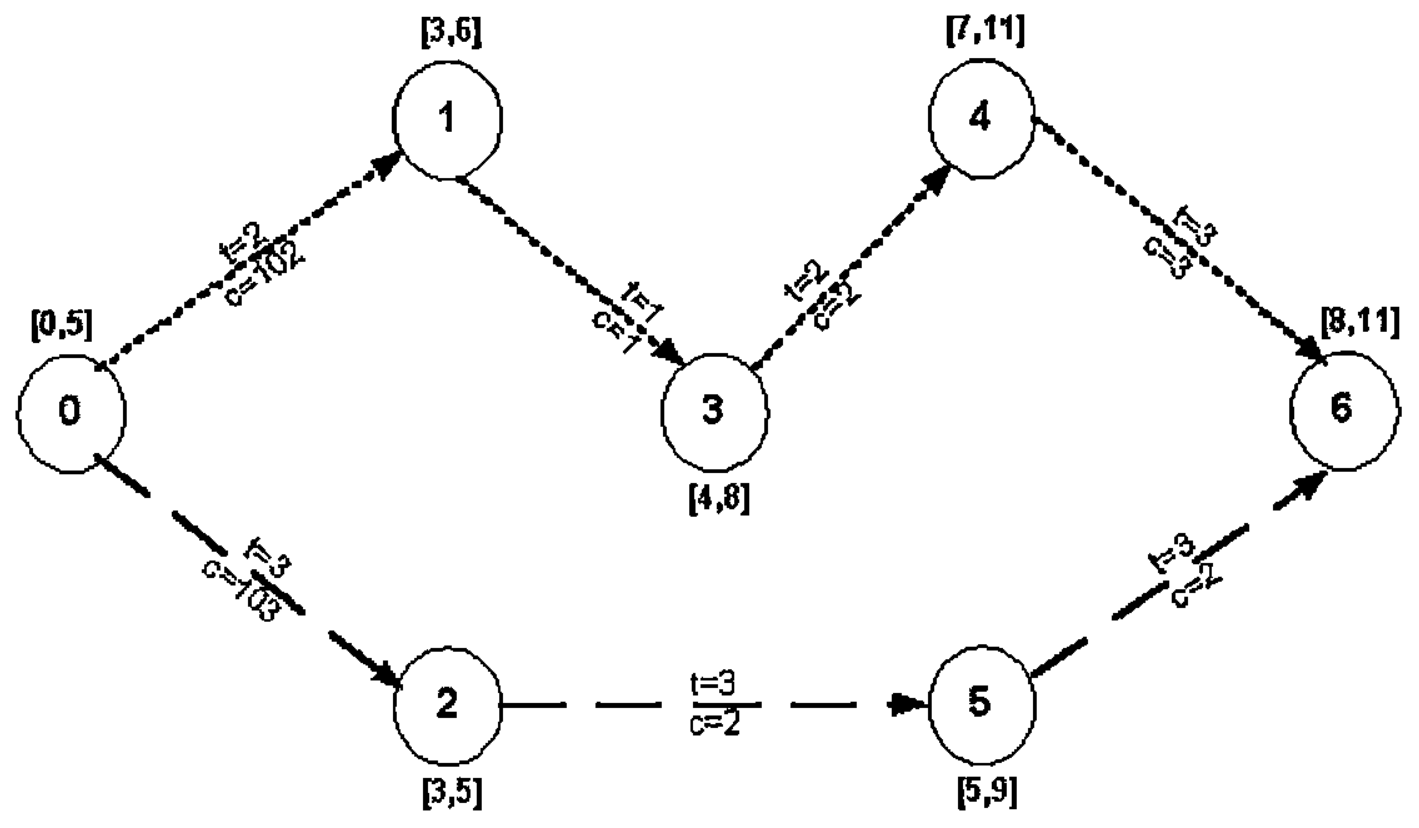

Figura 4.5: Caminhos ótimos (em tracejado) encontrados após a resolução do problema 


\section{Capítulo 5}

\section{Pr blema de Caminho Mínimo com Janela de Tempo}

\subsection{Considerações Iniciais}

Neste capítulo revisamos um algoritmo para resolver o problema de caminho mínimo com restrições de janela de tempo.

Segundo [Desrochers \& Soumis, 1988], o problema de caminho mínimo com janela de tempo (CMJT) consiste em encontrar o caminho de menor distância, ou menor custo, entre um nó de origem e um nó de destino de uma rede, respeitando-se as restrições de horário de atendimento (janela de tempo) em cada um dos nós do caminho.

Este problema foi originalmente formulado por [Desrosiers et al., 1983], como um subproblema da construção de um roteiro. Os autores formularam um princípio de otimilidade que consiste em uma generalização do método de Bellman (Gallo e Pallotino (1984)), mais conhecido como o método das etiquetas, permitindo um tratamento eficiente das mesmas.

[Desrosiers et al., 1984] sugeriu a utilização do algoritmo de caminho mínimo com janelas de tempo para a resolução do subproblema de geração de colunas, resultante da decomposição do problema de roteamento e programação de veículos escolares utilizando o método de geração de colunas. Este assunto foi abordado em detalhes no capítulo 4.

No problema abordado no capítulo 4, as restrições de janela de tempo e os tempos de viagem positivos nos arcos asseguram que os caminhos gerados sejam finitos. Por outro lado, não permite assegurar que nós do caminho não sejam visitados mais de uma vez.

O algoritmo a ser revisado, proposto por [Desrosiers et al., 1983] segue a generalização do Método de Ford-Bellman-Moore. 


\subsection{Formulação do Problema}

Como vimos no capítulo 4, um caminho de comprimento mínimo entre os nós $s$ e $t$, respeitando as restrições de horários (janelas do tempo) é obtido encontrando a solução ótima do seguinte modelo:

$$
\begin{aligned}
& \text { Minimizar } \sum_{(i, j) \in A} c_{i j} x_{i j} \\
& \text { sujeito } a: \sum_{j \in \mathbb{N}} x_{i j}=\sum_{j \in N} x_{j i} \quad i \in P \\
& \sum_{j \in P} x_{s j}=1 \\
& \sum_{j \in P} x_{j t}=1 \\
& x_{i j}>0 \Rightarrow t_{i}+t_{i j} \leq t_{j} \quad(i, j) \in I \\
& a_{i} \leq t_{i} \leq b_{i} \\
& i \in P \\
& x_{i j}=\{0,1\} \\
& (i, j) \in A
\end{aligned}
$$

Os coeficientes da função objetivo 5.1 que denotamos por $c_{i j}$ a cada iteração do algoritmo simplex com geração de colunas (estudado no capítulo 4) é alterado para $c_{i j}-\pi_{i j}$ podendo assumir valores positivos ou negativos.

\subsection{Algoritmo de Ford-Bellman-Moore}

Antes de discutirmos a generalização, lembramos que o algoritmo de Ford-BellmanMoore para o problema de caminho mínimo (sem janela de tempo), determina para cada nó uma etiqueta $\theta_{i}$ que representa o custo de ir da origem $s$ para o nó $i$ utilizando a rota de custo mínimo. As etiquetas são melhoradas recursivamente até que os valores ótimos sejam obtidos.

Seja $F(i)=\{j:(i, j) \in A, j \in \mathbb{N}\}$ o conjunto de sucessores do nó $i$ e $L$ o conjunto de nós que ainda não foram explorados. A árvore de caminho mínimo saindo da origem $s$ para todos os outros nós da rede é obtida associando-se a cada nó uma etiqueta que é melhorada a cada iteração do algoritmo. O método das etiquetas consiste na escolha de um nó $i$ pertencente ao conjunto $L$, em seguida retira-se o nó $i$ do conjunto $L$ e tenta-se melhorar todos os sucessores do nó $i$. Logo, o novo nó melhorado é inserido no conjunto $L$. Assim, quando o conjunto $L$ for vazio, a etiqueta $\theta_{i}$ associada ao nó $i$ representará o caminho de comprimento mínimo saindo da origem $s$ e terminando no nó $i$. 
A seguir temos os principais passos do algoritmo.

Passo 0: Inicialização

- o custo na origem $s: \theta_{s}=0$

- 0 custo nos demais nós: $\theta_{i}=\infty \quad i \neq s$.

$-L=\{s\}$

Passo 1: Escolha um nó $i \in L$

- construindo $F(i)$, conjunto de sucessores do nó $i$

- $\forall j \in F(i)=\{j:(i, j) \in A, j \in \mathbb{N}\}$ tal que: $\theta_{j}>\theta_{i}+c_{i j}$, dado que $\theta_{j}=\theta_{i}+c_{i j}$

$L=L \cup\{j\}$

Passo 2: Redução do conjunto $L$

$-L=L-\{i\}$

- Se $L=\varnothing$ então FIM.

- Senão, retorne ao Passo 1.

\subsection{Natureza das Etiquetas}

Para resolvermos o problema de caminho mínimo com janela de tempo, as rotas têm outro atributo importante que consiste no tempo de chegada até ao nó $i$. Então, para tratarmos simultaneamente as variáveis de tempo $t_{i}$ e as variáveis de custo $\theta_{i}$ associadas a cada nó $i$, utilizaremos uma etiqueta formada por $\left(t_{i}, \theta_{i}\right)$ para rotular cada nó $i$.

Uma etiqueta $\left(t_{i}, \theta_{i}\right)$ é atribuída ao nó $i$ se, e somente se, existir um caminho possível de custo $\theta_{i}$, saindo da origem $s$ e chegando ao nó $i$ no menor tempo $t_{i}$. Qualquer caminho saindo da origem $s$ e chegando ao nó $i$ com um custo $\theta_{i}$ e com o tempo pertencente ao intervalo $\left[t_{i}, b_{i}\right]$ não tem custo de espera.

No algoritmo de Ford-Bellman-Moore, o problema clássico do Caminho Mínimo, associa a cada nó uma única etiqueta que é progressivamente melhorada. Quando acrescentamos ao problema as restrições de horários (janela de tempo) não é mais possível conservar unicamente a etiqueta melhorada para cada nó, porque o par $\left(t_{i}, \theta_{i}\right)$ não tem ordem total no $\mathbb{R}^{2}$ : então é necessário preservar um conjunto de etiquetas $\left(t_{i}^{\alpha}, \theta_{i}^{\alpha}\right), \alpha \geq 1$. Este conjunto é finito porque a quantidade finita de nós e a janela de tempo, determinam 
um número finito de caminhos possíveis saindo da origem $s$ e chegando ao nó $i$, e cada caminho produz uma etiqueta. Estas etiquetas formam para cada nó i uma lista $Q_{i}$. A lista $Q_{j}$ é atualizada sequencialmente a partir das informações em $Q_{i}$ mais as informações encontradas ao considerar os caminhos de $s$ a $j$, compostas do caminho de $s$ a $i$ do arco $(\mathbf{i}, \mathbf{j})$.

\subsection{Relação de Ordem das Etiquetas}

Construímos para cada nó $i$ um conjunto de etiquetas $Q_{i}$ que guarda as menores distâncias referentes aos diferentes tempos localizados no intervalo $\left[a_{i}, b_{i}\right]$. Definimos então a relação de ordem parcial $\prec$ para o nó $i$ :

$$
\left(t_{i}^{1}, \theta_{i}^{1}\right) \prec\left(t_{i}^{2}, \theta_{i}^{2}\right) \Leftrightarrow\left(t_{i}^{1} \leq t_{i}^{2}\right) \text { e }\left(\theta_{i}^{1} \leq \theta_{i}^{2}\right)
$$

Uma etiqueta pertencente ao conjunto $Q_{i}$ é denominada etiqueta mínima se não existir uma outra etiqueta inferior a ela segundo esta relação de ordem. Assim, as etiquetas mínimas guardam o comprimento do caminho ótimo da origem $s$ ao destino $i$. Um conjunto de etiquetas é dito irredutível se todas as etiquetas são mínimas. Uma etiqueta mínima é uma etiqueta ótima $\left(t_{i}^{*}, \theta_{i}^{*}\right)$ se, quando aplicarmos o princípio de otimalidade (se sabemos os caminhos mínimos de todos os predecessores de $j$, então, podemos determinar o caminho mínimo até $j$ ) a esta etiqueta, ela continuar com o menor caminho satisfazendo as restrições de horário em relação as outras etiquetas do conjunto. O resultado desta aplicação permite reduzir o conjunto de etiquetas de cada nó retirando aquelas que não são mínimas e conservando o conjunto das etiquetas irredutíveis dentro do tempo de atendimento permitido. O conjunto irredutível associado ao nó $i$ é ordenado em função da variável de tempo que é estritamente crescente, observando que os comprimentos $\theta_{i}$ estão em ordem decrescente, como mostra a figura 5.1.

O conjunto irredutível associado ao nó $i$ contém $\alpha(i)$ pares de etiquetas: $\left(t_{i}^{\alpha}, \theta_{i}^{\alpha}\right)$, $\alpha=1,2, \ldots, \alpha(i)$, com

$$
a_{i} \leq t_{i}^{1}<t_{i}^{2}<\cdots<t_{i}^{\alpha(i)} \leq b_{i} \quad \text { e } \quad \theta_{i}^{1}>\theta_{i}^{2}>\cdots>\theta_{i}^{\alpha(i)}
$$

Para a etiqueta $\alpha, \theta_{i}^{\alpha}$ é a distância mais curta da origem $s$ ao nó $i$ dentro do seguinte intervalo de tempo:

$$
\begin{aligned}
& {\left[t_{i}^{\alpha}, t_{i}^{\alpha+1}\right] \text { se } \alpha=1,2, \ldots, \alpha(i)-1} \\
& {\left[t_{i}^{\alpha(i)}, b_{i}\right] \text { c.c. }}
\end{aligned}
$$




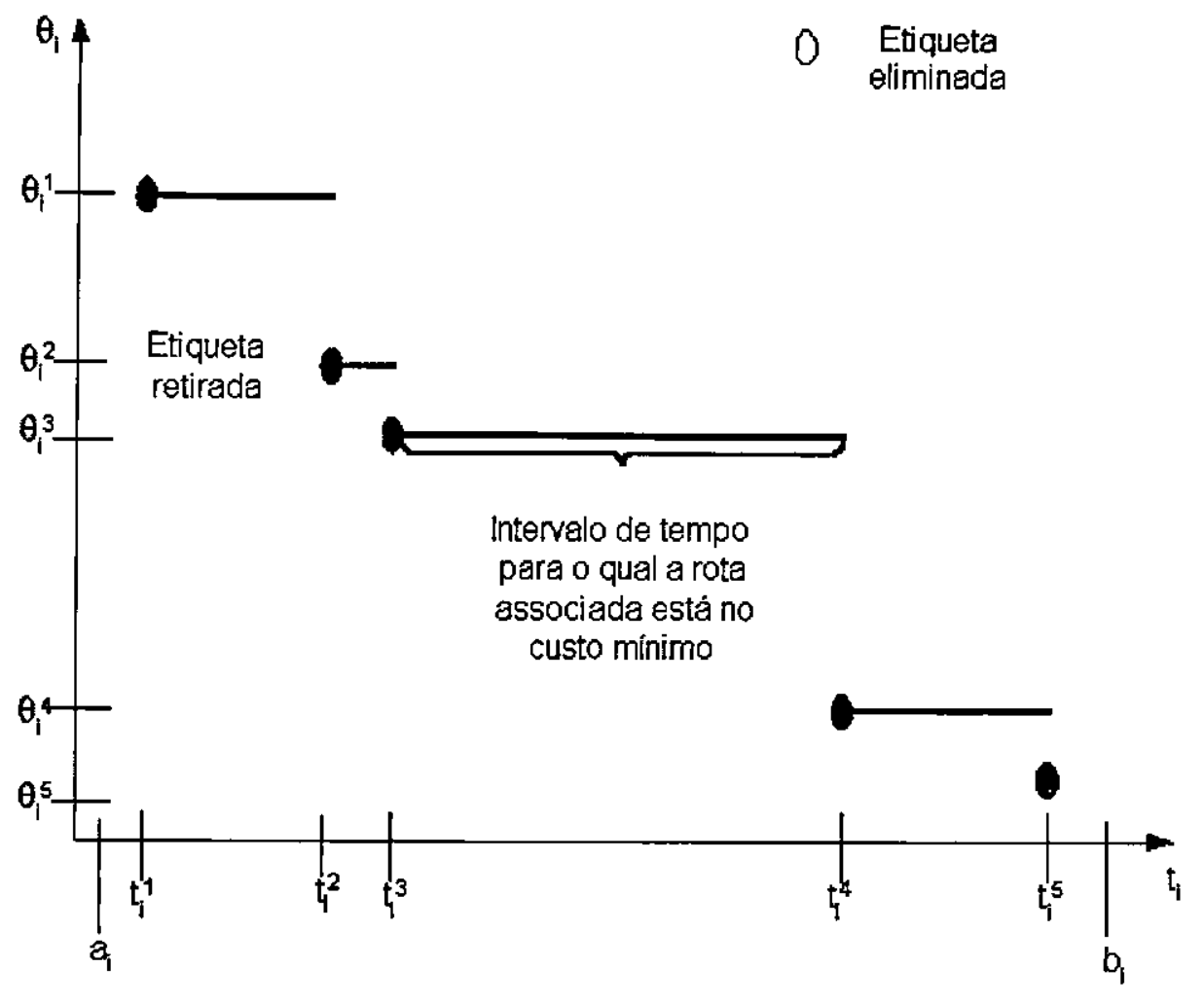

Figura 5.1: Custo $\mathrm{x}$ Tempo de Chegada de etiquetas armazenadas no nó i

\subsection{Algoritmo de Caminho Mínimo com Janela de Tempo}

Descreveremos então o algoritmo de caminho mínimo para uma rede com as restrições de horários nos nós, de modo similar ao algoritmo de Ford-Bellman-Moore.

Este algoritmo armazena em cada nó pares de etiquetas $\left(t_{i}, \theta_{i}\right)$, ou seja, rotas de custo mínimo chegando ao nó $i$, no tempo $t_{i}$.

Seja $Q_{i}=\left(t_{i}^{\alpha}, \theta_{i}^{\alpha}\right), \alpha=1,2, \ldots, \alpha(i)$, um conjunto irredutível de etiquetas associadas ao nó $i$. Assim, unindo o arco $(i, j)$ aos caminhos que saem da origem $s$ e chegam em $i$, obtemos o conjunto $Q_{j}$ associado ao nó $j$ através da seguinte aplicação:

$$
F_{i j}\left(Q_{i}\right)=\cup_{\alpha} f_{i j}\left\{\left(t_{i}^{\alpha}, \theta_{i}^{\alpha}\right)\right\}
$$

onde

$$
f_{i j}\left\{\left(t_{i}^{\alpha}, \theta_{i}^{\alpha}\right)\right\}= \begin{cases}\left\{\left(\max \left[a_{j}, t_{i}^{\alpha}+t_{i j}\right], \theta_{i}^{\alpha}+c_{i j}\right)\right\} & \text { se } t_{i}^{\alpha}+t_{i j} \leq b_{j} \\ \varnothing & \text { caso contrário. }\end{cases}
$$


A definição de $f_{i j}$ permite um tempo de espera no nó $j$, quando o tempo de chegada for menor que o limitante inferior da janela de tempo. $O$ novo conjunto $F_{i j}\left(Q_{i}\right)$ não é necessariamente irredutível, pois etiquetas que não sejam minimais podem ser geradas.

Denotamos por $\overline{F_{i j}\left(Q_{i}\right) \cup Q_{j}}$ a redução de $F_{i j}\left(Q_{i}\right) \cup Q_{j}$ conservando apenas as etiquetas mínimas. As etiquetas associadas a um nó estão localizadas dentro de uma lista com os tempos em ordem crescente.

A seguir mostraremos os principais passos do Algoritmo de Etiquetamento para Problemas de Caminho Mínimo com Janelas de Tempo:

Passo 0: Inicialização

- $Q_{0}=\left\{\left(t_{s}^{1}=a_{s}, \theta_{s}^{1}=0\right)\right\}$

- $Q_{i}=\left\{\left(t_{i}^{1}=a_{i}, \theta_{i}^{1}=\infty\right)\right\}$ para $i \neq s$

$-L=\{s\}$

Passo 1: Explorando $F(i)$

- Escolha em nó $i \in L$

- Calcular $F(i)=\{j:(i, j) \in A, j \in N\}$, onde

$A=$ conjunto de arcos,

$N=\{1,2, \ldots, n\}$ conjunto de nós, e

$L=$ conjunto de nós ainda não explorados.

$-\forall j \in F(i)$ tal que $\overline{F_{i j}\left(Q_{i}\right) \cup Q_{j}} \neq Q_{j}$

Onde: $\left\{\begin{array}{l}F_{i j}\left(Q_{i}\right)=\cup_{\alpha} f_{i j}\left\{\left(t_{i}^{\alpha}, \theta_{i}^{\alpha}\right)\right\} \\ \left.f_{i j}\left\{t_{i}^{\alpha}, \theta_{i}^{\alpha}\right)\right\}=\left\{\max \left[a_{j}, t_{i}^{\alpha}+t_{i j}\right], \theta_{i}^{\alpha}+c_{i j}\right\}, \text { se } t_{i}^{\alpha}+t_{i j} \leq b_{j}\end{array}\right.$

- atualização:

$$
\begin{aligned}
& Q_{j}=\overline{F_{i j}\left(Q_{i}\right) \cup Q_{j}}, \\
& L=L \cup\{j\}
\end{aligned}
$$

Passo 2: Redução de $L$

- $L=L-\{i\}$

- se $L=\varnothing$ então FIM

- senão, retorna ao passo 1 . 


\subsection{Considerações Finais}

O algoritmo apresentado na seção 5.6 foi implementado na linguagem $\mathrm{C}++$ utilizando para tanto o ambiente de programação Microsoft ${ }^{\circledR}$ Visual $\mathrm{C}++$.

Um pequeno exemplo ilustra como os dados são fornecidos e como as soluções são obtidas.

Os dados de entrada são lidos de um arquivo texto conforme apresentado na tabela 5.1. Estes dados correspondem à rede representada na figura 5.2.

\begin{tabular}{||c|cl|c|c|c|c||}
\hline Nó & Janela de Tempo & $\mathrm{N}^{\circ}$ de Predecessores & Predecessor & Tempo & Custo \\
\hline $\mathrm{s}=0$ & 2 & 7 & 0 & 0 & 0 & 0 \\
\hline 1 & 2 & 5 & 1 & 0 & 1 & 2 \\
\hline 2 & 3 & 6 & 2 & 0 & 2 & 1 \\
& & & & 1 & 2 & 3 \\
\hline 3 & 2 & 7 & 2 & 1 & 2 & 3 \\
& & & 3 & 2 & 3 & 2 \\
\hline 4 & 4 & 8 & & 1 & 2 & 1 \\
& & & & 3 & 3 & 7 \\
& & & & 3 & 2 & 10 \\
\hline$t=5$ & 5 & 10 & & 4 & 2 & 2 \\
\hline
\end{tabular}

Tabela 5.1: Dados de entrada para o arquivo

Ao término de execução do programa, temos todos os possíveis caminhos mínimos, saíndo da origem $s$ (nó 0 ) e chegando ao depósito $t$ (nó 5 ). O resultado é mostrado em um arquivo de saída conforme mostra a tabela 5.2:

\begin{tabular}{|c|c|c|c|}
\hline \multicolumn{4}{|c|}{ 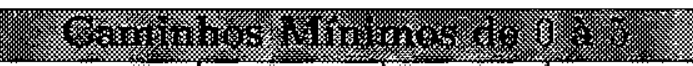 } \\
\hline Caminho & Rota & Tempo & Custo $_{\text {. }}$ \\
\hline 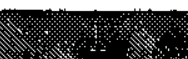 & 0145 & 7 & 5 \\
\hline
\end{tabular}

Tabela 5.2: Dados de saída do arquivo

Veja na figura 5.3 o correspondente grafo representando todos os possíveis caminhos mínimos.

No capítulo 4, o problema (CMJT) tem seus custos atualizados de acordo com os multiplicadores simplex $\pi_{i}$, que orientam se o caminho mínimo deve passar ou não por determinados nós da rede. Por exemplo, se o multiplicador simplex $\pi_{i} \geq 0$ então $c_{i j}-\pi_{i j}$ diminui, indicando se o caminho mínimo deverá conter o nó $i$. 


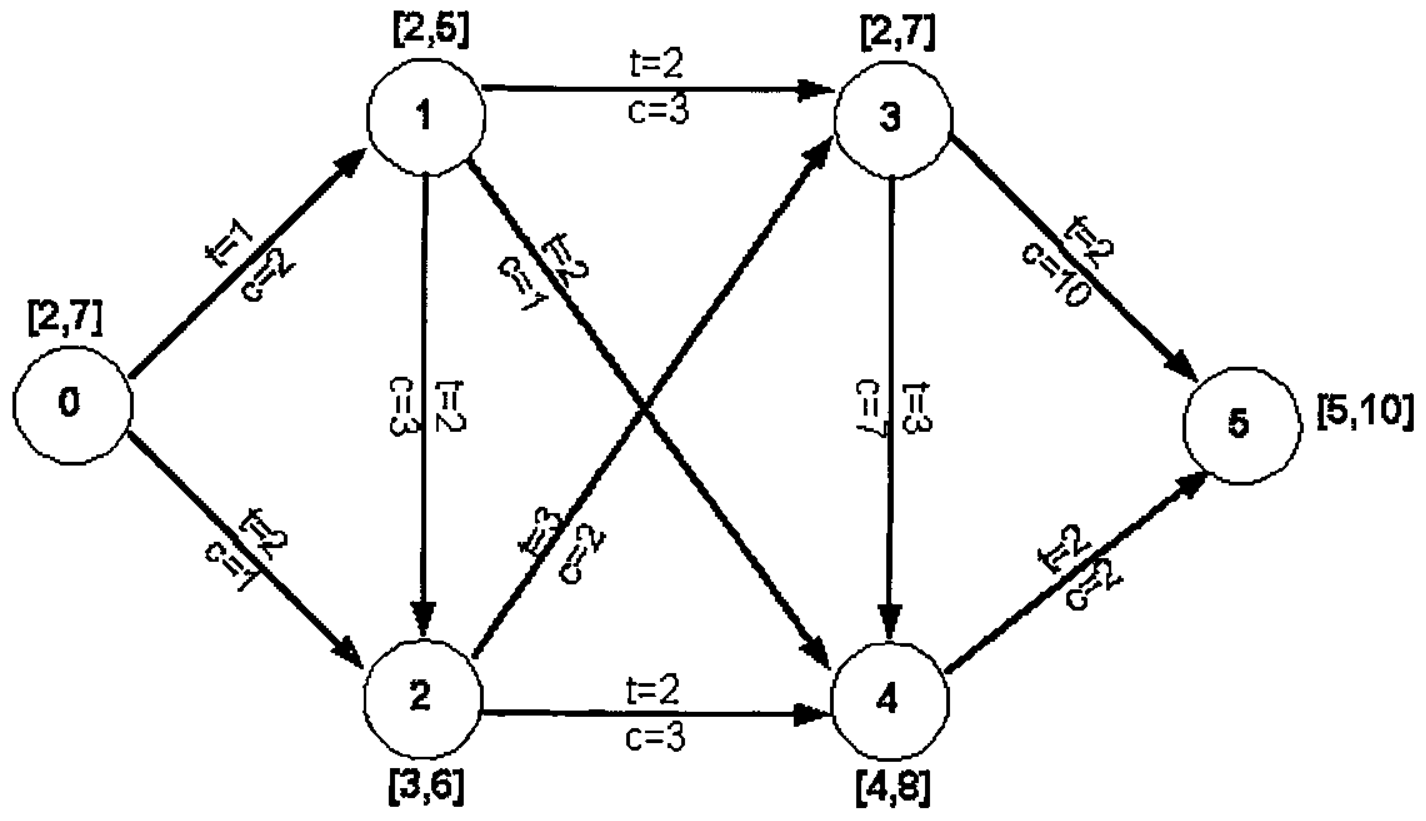

Figura 5.2: Grafo representando os dados de entrada para o arquivo

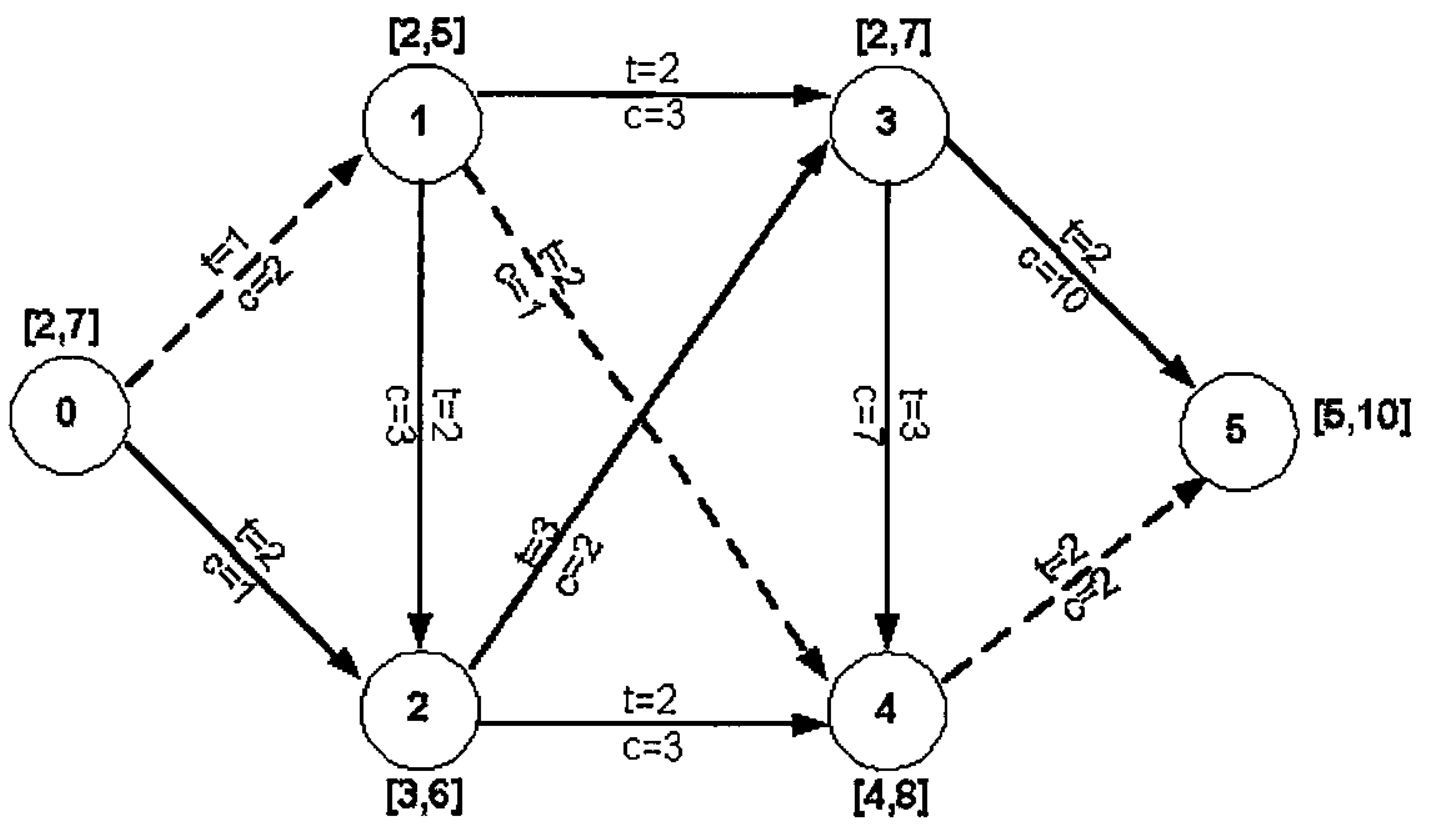

Figura 5.3: Grafo representando o caminho mínimo da origem ao destino

Tomamos sem perda de generalidade o nó 3 como exemplo, para explicar essa afirmação. Associamos ao nó 3 o correspondente multiplicador simplex $\pi_{3}=10$. Logo, os sucessores do nó 3 terão um novo custo:

$$
\begin{aligned}
& c_{35}-\pi_{3}=10-10=0 \\
& c_{34}-\pi_{3}=7-10=-3
\end{aligned}
$$


Executando novamente o programa (CMJT) obtemos novos caminhos. O conjunto $Q_{5}$ torna-se:

$$
\begin{array}{lll}
\text { caminho 1: } 0-1-3-5 & \text { tempo: } 7 & \text { custo: } 5 \\
\text { caminho 2: } 0-1-4-5 & \text { tempo: } 7 & \text { custo: } 5 \\
\text { caminho 3: } 0-2-3-5 & \text { tempo: } 9 & \text { custo: } 3
\end{array}
$$

Como os três caminhos satisfazem a janela de tempo, tomamos então o de menor custo, ou seja:

$$
\text { caminho mínimo: } 0-2-3-5
$$

Observe que o caminho do nó 3 ao nó 5 , passando pelo nó 4 é mais barato, porém viola a restrição de janela de tempo no nó 4. 


\section{Capítulo 6}

\section{Conclusões e Trabalhos Futuros}

Neste trabalho revisamos a técnica de geração de colunas aplicada a problemas de roteamento de veículos, onde subproblemas como caminho mínimo com janela de tempo e mochila surgem naturalmente, os quais incluem parte significativa da natureza combinatória do problema original. Esta técnica tem sido utilizada com sucesso em problema de otimização combinatória e neste trabalho revisamos sua aplicação a dois problemas de difícil solução com resultados bastante promissores.

Estudamos a Técnica de Geração de Colunas (TGC) e sua aplicação para resolver problemas de roteamento de veículos. No decorrer do desenvolvimento da dissertação foi feita uma breve revisão na literatura a qual contribuiu para uma melhor compreensão dos problemas de otimização combinatórios, dando uma ênfase maior aos PRVs.

Durante o estudo da (TGC) foi feita uma revisão do Método Simplex e do Problema de Corte de Estoque Unidimensional, um exemplo didático o qual solidificou a compreensão da técnica em estudo. Por fim, estudamos duas importantes classes de problemas de roteamentos onde essa técnica é aplicada:

- o problema de roteamento de helicópteros em plataformas marítimas, onde cada coluna da matriz é gerada resolvendo-se um Problema da Mochila juntamente com vários caixeiros viajantes;

- o problema de roteamento com janela de tempo, onde cada coluna com o menor custo relativo é gerada resolvendo-se o problema do Caminho Mínimo com as restrições horárias.

Como vimos no capítulo 5, para resolver o problema de caminho mínimo foi implementado o algoritmo de Caminho Mínimo com Janela de Tempo (CMJT) desenvolvido por [Desrosiers et al., 1983]. Esse algoritmo foi posteriormente combinado com o algoritmo Primal simplex para resolver problemas de roteamento onde uma frota deve ser dimensionada . 


\subsection{Trabalhos Futuros}

Um próximo trabalho seria a aplicação desta implementação em problemas de roteamento que surgem na prática, incluíndo as restrições especiais. Esta implementação poderá ser aplicada no trabalho de [Pereira.,et al,1998] descrito abaixo. E avaliar os possíveis resultados.

[Pereira.,et al,1998] estudaram um problema de roteamento de veículos com janela de tempo aplicado em uma micro-usina de beneficiamento de leite situada em uma cidade média do interior de São Paulo (cerca de 170 mil habitantes). Tendo como objetivo minimizar a distância percorrida para diminuir o custo de transporte e, também, porque o leite e seus derivados são produtos de alta perecibilidade, exigindo o mínimo tempo de exposição à temperatura ambiente para garantir sua qualidade. O programa consiste na entrega diária de 2500 litros de leites e 150 litros de iorgute, em 108 pontos comerciais na cidade (sendo estes bares, padarias, varejōes, supermercados e sorveteria). A empresa possui sua própria frota de veículos, composta de caminhões isotérmicos e peruas. Em alguns pontos comercias há um intervalo de horário fixo para o recebimento dos produtos distribuídos pela empresa, que deve ser respeitado. Portanto, para o planejamento e otimização da rota serão levadas em consideração as janelas de tempo.

A técnica de geração de colunas aplicada ao problema de roteamento com janela de tempo parece ser bem promissora, seja pela relativa simplicidade de implementação, como pela capacidade de tratar problemas bastante gerais, uma vez que parte da natureza combinatória do problema é passada ao sub-problema. Uma pesquisa futura poderia examinar outros problemas de roteamento, por exemplo, diferentes tipos de veículos, de capacidades e desempenhos diferenciados e em quantidades limitadas.

Além disso, a geração de colunas resolve a aproximação linear do problema de partição de conjunto, merecendo maior atenção na elaboração de heurísticas de arredondamento de solução, como é feito para o problema de corte de peças de estoque. 


\section{Referências Bibliográficas}

[Arenales \& Morabito, 1997] Arenales, M. N. Morabito, R. (1997). Mini Curso: O Problema de Corte e Empacotamento e Aplicações Industriais. Relatório técnico, XX CNMAC - Congresso Nacional de Matemática Aplicada e Computacional, Gramado-RS.

[Bazarra et al., 1990] Bazarra, M. S., Jarvis, J. J., Sherali, H. D. (1990). Linear Programming and Network Flows. Wiley, New York.

[Bodin et al., 1983] Bodin, L. D., Assad, A., Ball, M., Golden, B. (1983). The State of the Art in Routing Scheduling of Vehicles and Crews. Compt. Opns., 10.

[Boldin \& Golden, 1981] Boldin, L. D. Golden, B. L. (1981). Classification in Vehicle Routing and Scheduling. Networks, 11:97-108.

[Bramel \& Levi, 1997] Bramel, J. Levi, D. S. (1997). On the Effectiveness of Set Covering Formulations For the Vehicle Routing Problem With Time Windows. Operations Research, 40:295-301.

[Brinati et al., sd] Brinati, M. A., Botter, R. C., Roque, J. R. R., Gouvea, M. T., Souza, R. L., Carneiro, P. R. B. (sd). Aplicação de Heurísticas de Roteamento Para o Dimensionamento de Uma Frota de Transporte Marítimo. Relatório técnico, CEPEN-USP, São Paulo.

[Cunha, 1991] Cunha, C. B. (1991). Algoritmos para Roteamento e Programação de Veículos no contexto da Distribuição Física. Dissertação de Mestrado, Departamento de Engenharia de Transportes-EP/USP, São Paulo.

[Cunha, 1997] Cunha, C. B. (1997). Uma Contribuição para o Problema de Roteirização de Veículos com Restrições Operacionais. Tese de Doutorado, Departamento de Engenharia de Transportes-EP/USP, São Paulo.

[Cunha, 2000] Cunha, C. B. (2000). Aspectos Práticos da Aplicação de Modelos de Roteirização de Veículos a Problemas Reais. Transportes, 8(2). 
[Dantzig \& Wolfe, 1960] Dantzig, G. B. Wolfe, P. (1960). Decomposition Principle for Linear Prograrns. Operations Research, 8(1):101-111.

[Desrochers et al., 1992] Desrochers, M., Desrosiers, J., Solomon, M. (1992). A New Optimization Algorithm for the Vehicle Routing Problem With the Windows. Operation Research, 40:342-354.

[Desrochers \& Soumis, 1988] Desrochers, M. Soumis, F. (1988). A Generalized Permanent Labelling Algorithm for the Shortest Path Problem With Time Windows. INFOR. 26.

[Desrosiers et al., 1983] Desrosiers, J., Pelletier, P., Soumis, F. (1983). Plus Court Chemin Avec Contraintes d'Horaires. RAIRO, 17:357-377.

[Desrosiers et al., 1984] Desrosiers, J., Soumis, F., Desrochers, M. (1984). Routing with Time Windows by Column Generation. Networks, 10:545-565.

[Desrosiers et al., 1986] Desrosiers, J., Soumis, F., Desrochers, M., Sauvé, M. (1986). Methods for Routing With Time Windows. European Journal of Operational Research, 23:236-245.

[Fisher \& Jaikumar, 1981] Fisher, M. Jaikumar, R. (1981). A Generalized Assingnment Heuristics for Vehicle Routing. Networks, 11:109-124.

[Fisher et al., 1997] Fisher, M. L., Jörnsten, K. O., Madsen, O. B. G. (1997). Vehicle Routing With Time Windows: Two Optimization Algorithms. Operations Research, 45:488-492.

[Gilmore \& Gomory, 1961] Gilmore, P. C. Gomory, R. E. (1961). A Linear Programming Approach to the Cutting Stock Problem. Operations Research, 9:849-859.

[Gilmore \& Gomory, 1965] Gilmore, P. C. Gomory, R. E. (1965). Multi-stage Cutting Stock Problems of Two and More Dimensions. Operations Research, 13:94-120.

[Goldbarg, 2000] Goldbarg, M. C. (2000). Otimização Combinatória e Programação Linear: Modelos e Algoritmos. Campus, Rio de Janeiro.

[Larson \& Odoni, 1981] Larson, R. Odoni, A. (1981). Urban Operations Research. Prentice - Hall.

[Luemberger, 1973] Luemberger, D. G. (1973). Introduction to Linear and Nonlinear Programming. Addison - Wesley. 
[Nemhauser \& Wolsey, 1988] Nemhauser, G. Wolsey, L. A. (1988). Integer and Combinatorial Optimization. Wiley, New York.

[Pereira et al., 1998] Pereira, M. A., Pelizaro, C., Silva, A. N. R. (1998). Uma Solução Apoiada em SIG para o Problema de Roteamento de Veículo em uma Cidade Média. Revista Universidade de Guarulhos - Ciências Exatas e Tecnlógias, 3(4).

[Pinto, 1999] Pinto, M. J. (1999). O Problema de Corte de Estoque Inteiro. Dissertação de Mestrado, Instituto de Ciências Matemáticas e de Computação-ICMC/USP, São Carlos.

[Pureza, 1990] Pureza, V. M. M. (1990). Problema de Roteamento de Vé́culos Via Metaheurística Tabu. Dissertação de Mestrado, Faculdade de Engenharia ElétricaUNICAMP, Campinas-SP.

[Pureza, 1996] Pureza, V. M. M. (1996). Abordagens Adaptativas de Metaheurísticas Tabu. Tese de Doutorado, Faculdade de Engenharia Elétrica-UNICAMP, Campinas-SP.

[Sierksma, 1996] Sierksma, G. (1996). Linear and Integer Programming: Theory and Practice. Marcel Dekker, New York.

[Sierksma \& Tijssen, 1998] Sierksma, G. Tijssen, G. A. (1998). Routing Helicopters for Crew Exchanges on Off - Shore Locations. Annals of Operations, 76:261-286.

[Solomon, 1986] Solomon, M. M. (1986). On The Worst-case Performance of Some Heuristics for the Vehicle Routing and Scheduling with Time Windows Constraints. Networks, 16:161-174.

[Wäscher \& Gau, 1996] Wäscher, G. Gau, T. (1996). Heuristics for the Integer OneDimensional Cutting Stock Problem: A Computational Study. OR Sperktrum, 18:131144. 